\title{
BEHAVIOUR OF PILE GROUP BEHIND A SHEET PILE QUAY WALL SUBJECTED TO LIQUEFACTION-INDUCED LARGE GROUND DEFORMATION OBSERVED IN SHAKING TEST IN E-DEFENSE PROJECT
}

\author{
RAmin Motamed ${ }^{\text {i) }}$, IKUo Towhataii), TSUYoshi Hondiii), \\ Susumu Yasuda ${ }^{\text {iv), }}$, Kentaro Tabata ${ }^{\mathrm{v})}$ and Hiroshi NaKazawa ${ }^{\mathrm{vi})}$
}

\begin{abstract}
This paper aims to illustrate a large-scale test on a pile group and a sheet pile quay wall which were subjected to liquefaction-induced large ground deformation. The sheet pile quay wall was displaced laterally and the $2 \times 3$ pile group was forced by the flow of liquefied soil. This experiment was conducted in March 2006 at the National Research Institute for Earth Science and Disaster Prevention (NIED), Hyogo Earthquake Engineering Research Center, Japan. Liquefaction-induced lateral spreading was achieved, and soil moved laterally about $1.1 \mathrm{~m}$ behind the sheet pile quay wall. Lateral soil displacement was measured by the inclinometers, and results were in close agreement with the directly observed values. Soil lateral displacement and velocity of soil flow decreased as the distance from the quay wall increased toward the landside. Bending strain records were able to explain the damages to the piles, yielding at the top and buckling at the middle height. Lateral force of the liquefied soil exerted on the piles was obtained using earth pressure (EP) sensors and it is shown that rear row piles (close to the quay wall) received larger lateral forces than front row piles (far from the quay wall). This behaviour is explained by the distribution of displacement and velocity of the liquefied soil throughout the shaking. In addition, the lateral soil force was back calculated from strain gauge data and the results are compared with the ones directly measured by the EP sensors. Then, the limitations and advantages of the back-calculation approach are elaborated in this study. Moreover, the time history of lateral soil force showed no correlation with either soil or pile displacements, while it demonstrated a fairly close correlation with the relative velocity until a specific time. This interesting finding would confirm the rate-dependent behaviour of the liquefied soil, though more data from large scale experiments, field testing and centrifuge model tests are needed in this regard.
\end{abstract}

Key words: large scale testing, liquefaction-induced large ground deformation, pile group (IGC: D7/E8/E12)

\section{INTRODUCTION}

Recently, performance-based design in geotechnical engineering is receiving great deal of attention, and many design codes initiated applying its concepts. As a result, the estimation of deformation of structures subjected to intense loadings, such as earthquakes, is becoming more important. According to numerous observations in the past, e.g., 1964 Niigata, 1983 Nihonkai-Chubu and 1995 Kobe earthquakes, pile foundations embedded in loose ground near a quay wall have received severe damages due to liquefaction-induced large ground displacement (Hamada et al., 1986; Tokimatsu and Asaka, 1998, among others). In this regard, physical modelling in geotechnics is a key measure to study the behaviour of differ- ent geotechnical structures including pile foundations and quay walls under the dynamic loading.

Imamura et al. (2004) investigated the response of pile groups to seismically induced lateral soil spreading using centrifuge model tests and found that the influence of both pile spacing and number of piles are significant. Moreover, they suggested an empirical formula for the total lateral force. Abdoun et al. (2003) presented the results of centrifuge model experiments on single and group piles subjected to earthquake-induced liquefaction and lateral spreading. Their results showed that maximum bending moment in layered ground configurations occurred at the boundaries between liquefied and nonliquefied layers.

The 1-g shaking table model test is one of the most

i) JSPS Postdoctoral Fellow, Department of Civil Engineering, Tokyo Institute of Technology, Japan (motamed@cv.titech.ac.jp) (formerly Ph.D. Student, Department of Civil Engineering, The University of Tokyo).

ii) Professor, Department of Civil Engineering, The University of Tokyo, Japan.

iii) Researcher, Takenaka Corporation, Japan.

iv) Professor, Department of Civil and Environmental Engineering, Tokyo Denki University, Japan.

v) Researcher, National Research Institute for Earth Science and Disaster Prevention (NIED), Japan.

vi) Project Researcher, Port and Airport Research Institute (PARI), Japan.

The manuscript for this paper was received for review on July 1, 2008; approved on March 26, 2009.

Written discussions on this paper should be submitted before January 1, 2010 to the Japanese Geotechnical Society, 4-38-2, Sengoku, Bunkyo-ku, Tokyo 112-0011, Japan. Upon request the closing date may be extended one month. 
common tools in the field of experimental geotechnical engineering. However, limitation of the size of the model decreases its efficiency. To overcome this disadvantage, large shaking table tests were initiated mainly in Japan in which a similar stress level as the prototype is reproduced (Cubrinovski et al., 2006; Orense et al., 2000, among others). Tokimatsu and Suzuki (2004) and Tokimatsu et al. $(2001,2005)$ reported several large scale shaking table tests on pile groups, and investigated in particular the cyclic behaviour of the soil-pile-structure model. However, in liquefaction-induced large ground deformation, the monotonic component of lateral load becomes dominant.

The behaviour of piles in liquefied sand has been also studied through field testing by several researchers. For example, Rollins et al. (2005a, b) studied behaviour of piles in the liquefied soil using explosives to reproduce the liquefaction. However, in these field tests, the pile group was pulled by a loading frame; as a result, pile deflection was larger than soil deformation, while in liquefactioninduced lateral flow, soil displacement is significantly greater than pile deflection.

The rate-dependent behaviour of liquefied soil has been studied by several researchers through element testing (Nishimura et al., 2002; Gallage et al., 2005), 1-g shaking table model tests (Towhata et al., 1999; Gonzalez, 2004; Towhata et al., 2006; Motamed et al., 2007), and large scale shaking table tests (Tokimatsu et al., 2001). Generally, their findings are in close agreement indicating the correlation between the lateral pressure on piles and the velocity of soil flow when excess pore water pressure maintains high values.

The main objective of this paper is to investigate the behaviour of a pile group undergoing liquefaction-in- duced large ground displacement with special attention to the monotonic component of lateral force due to the lateral flow of liquefied soil. A large-scale test was carried out on a $2 \times 3$ pile group subjected to lateral spreading of liquefied sand behind a sheet pile quay wall. In this experiment, the pile group was significantly distressed by the liquefaction-induced large ground deformation; as a result, the pile foundation was severely damaged, and the quay wall was substantially displaced.

\section{E-DEFENSE SHAKING TABLE FACILITY}

The National Research Institute for Earth Science and Disaster Prevention (NIED) established the Hyogo Earthquake Engineering Research Center in Miki City, Hyogo Prefecture, Japan. This center which is called " $\mathrm{E}$ Defense" consists of a three-dimensional full-scale shaking table and other earthquake related research facilities, and the operation started in 2005. In this cutting-edge center, the world's largest shaking table $(20 \mathrm{~m} \times 15 \mathrm{~m})$ is located. Detailed information on the construction process and facility specifications can be found in Ogawa et al. (1999), Ohtani et al. (2003), Sato and Inoue (2003), MEXT and NIED (2006), and Tabata et al. (2007).

A special research project for earthquake disaster mitigation in urban areas was conducted in E-Defense from September 2002 to March 2007. The project was sponsored by the Ministry of Education, Culture, Sports, Science, and Technology (MEXT) and carried out by NIED. This mega project included six main research topics in which the test and analysis of soil-pile-structure systems was the experiment in the geotechnical engineering discipline. According to the research plan, two types

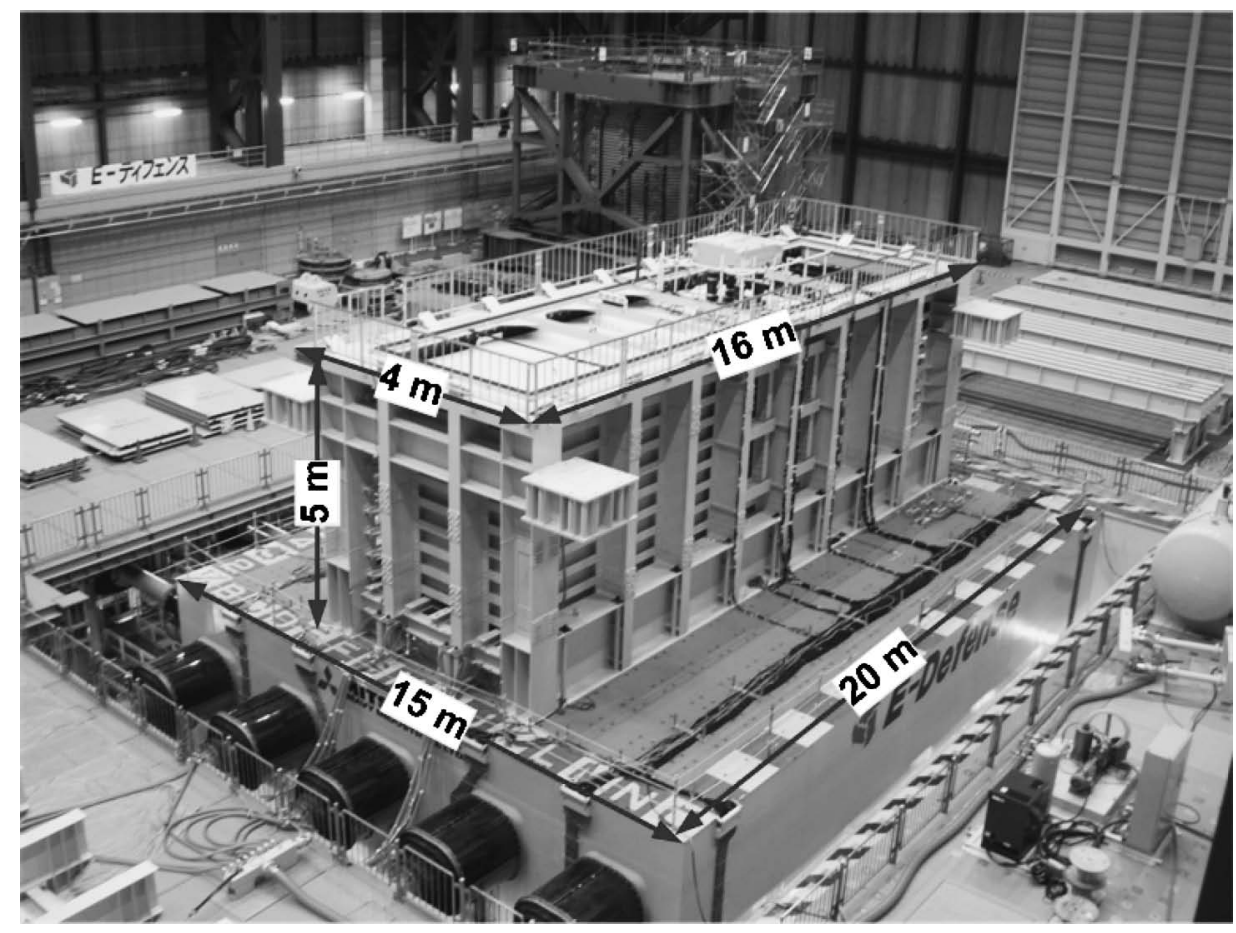

Fig. 1. Test on lateral spreading of liquefied sand behind sheet pile quay wall in E-Defense (March 2006) 


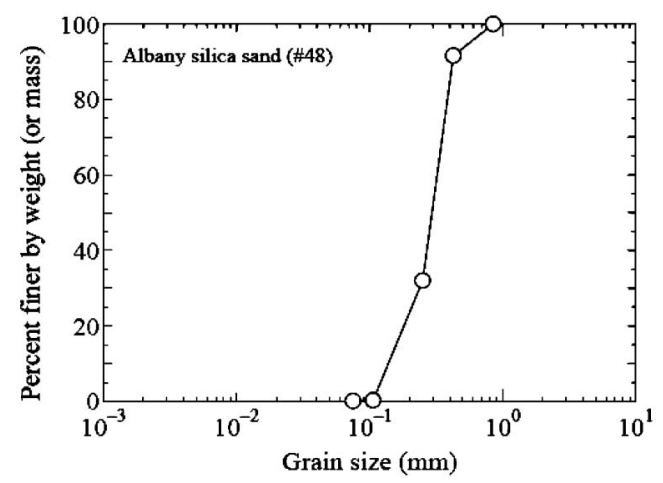

Fig. 2. Grain size distribution of Albany silica sand (MEXT and NIED, 2006)

Table 1. Basic geotechnical properties of Albany silica sand (MEXT and NIED, 2006)

\begin{tabular}{c|l}
\hline Specific gravity $\left(\mathrm{g} / \mathrm{cm}^{3}\right)$ & 2.63 \\
\hline Maximum void ratio, $\left(e_{\max }\right)$ & 0.783 \\
\hline Minimum void ratio, $\left(e_{\min }\right)$ & 0.513 \\
\hline Mean grain size, $D_{50}(\mathrm{~mm})$ & 0.2 \\
\hline Coefficient of uniformity, $U_{\mathrm{c}}$ & 1.64 \\
\hline
\end{tabular}

of the geotechnical tests were performed in 2006: (1) tests on soil-pile-structure interaction, and (2) a test on lateral spreading of liquefied sand behind a quay wall (Fig. 1). More information on the first type of tests can be found in Tokimatsu et al. (2007) and Suzuki et al. (2007), while the second type of tests is discussed in this paper, and the results are presented hereafter. There was a tremendous need for a sandy soil which is uniform, available in large quantities, and cheap. Therefore, it was decided that Albany silica sand will be imported from Australia to be used in the geotechnical tests. Figure 2 displays the grain size distribution and Table 1 provides the basic geotechnical properties of this sand.

\section{LARGE SCALE SHAKING TABLE TEST ON LATERAL FLOW OF LIQUEFIED SOIL BEHIND A SHEET PILE QUAY WALL}

A large-scale test on lateral spreading of liquefied sand behind a sheet pile quay wall was performed in March 2006 at E-Defense facility. Figure 3 displays the schematic plan and cross section views of the model which consisted of a $2 \times 3$ pile group located behind a sheet pile quay wall. Spacing between the piles in the group were 4 and 8.1 times the pile diameter $(D)$ in the directions parallel and perpendicular to the quay wall, respectively. The model was constructed in a huge rigid box with the dimensions of $16 \mathrm{~m} \times 5 \mathrm{~m} \times 4 \mathrm{~m}$. The ground consisted of

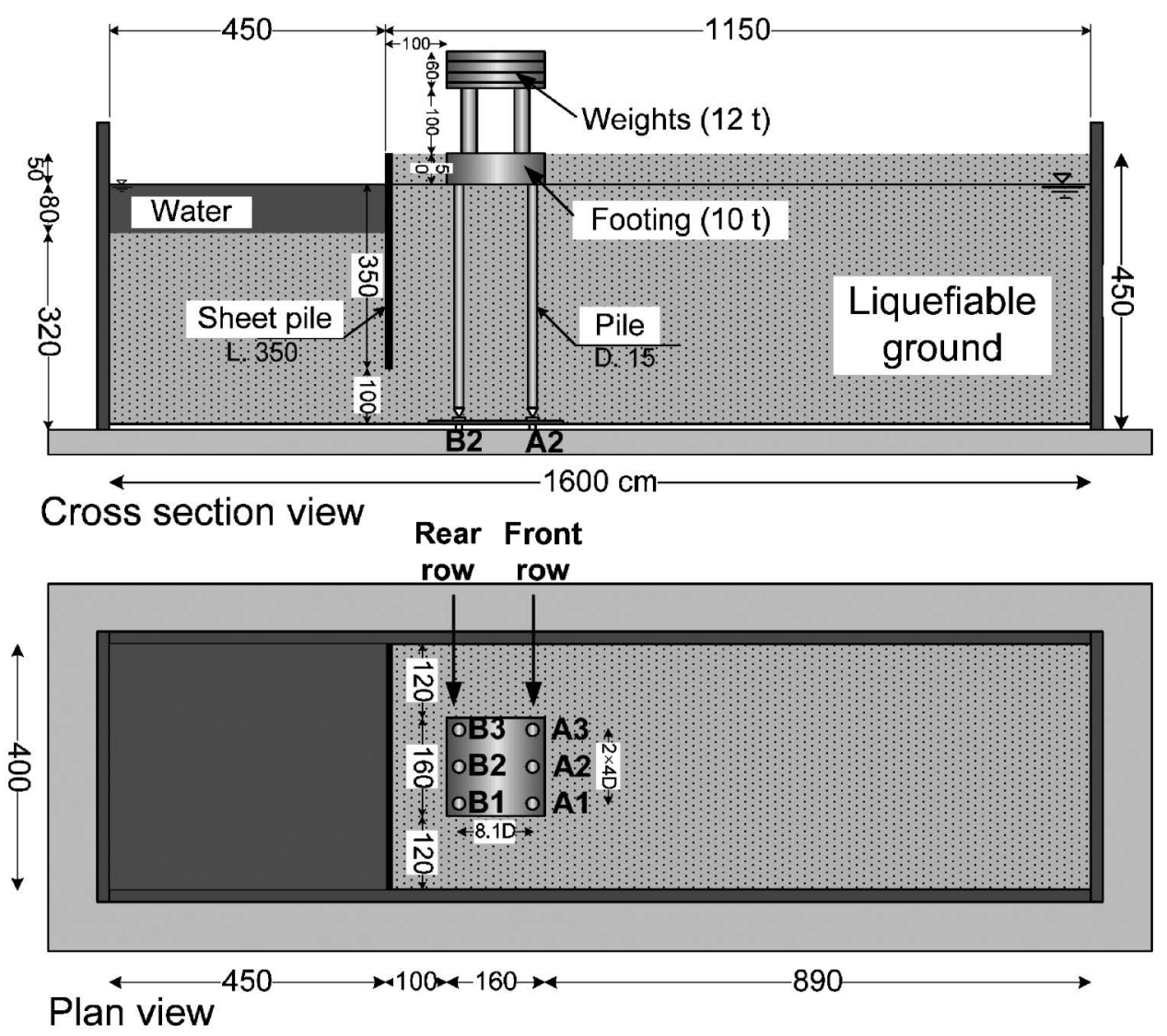

Fig. 3. Cross section and plan views of $2 \times 3$ pile group and sheet pile quay wall-large-scale test in E-Defense (unit: $\mathrm{cm}$ ) 
Table 2. Material properties of pile foundation and sheet pile quay wall

\begin{tabular}{c|c}
\hline Pile foundation & Sheet pile quay wall \\
\hline Hollow cylindrical steel & LSP-2 type \\
\hline Cross section area $\left(\mathrm{m}^{2}\right)$ & $\begin{array}{c}\text { Cross section area }\left(\mathrm{m}^{2}\right) \\
A=9.450 \times 10^{-4}\end{array}$ \\
$\begin{array}{c}\text { Moment of inertia }\left(\mathrm{m}^{4}\right) \\
I=2.672 \times 10^{-6}\end{array}$ & $\begin{array}{c}\text { Moment of inertia }\left(\mathrm{m}^{4}\right) \\
I=1.070 \times 10^{-6}\end{array}$ \\
\hline Modulus of elasticity $\left(\mathrm{N} / \mathrm{m}^{2}\right)$ & Modulus of elasticity $\left(\mathrm{N} / \mathrm{m}^{2}\right)$ \\
$E=2.06 \times 10^{11}$ & $E=2.06 \times 10^{11}$ \\
\hline Mass density $\left(\mathrm{t} / \mathrm{m}^{3}\right) M=7.9$ & Weight $(\mathrm{kgf} / \mathrm{m}) W=59.2$ \\
\hline Outer diameter $(\mathrm{mm}) D=152.4$ & \\
\hline Thickness $(\mathrm{mm}) t=2.0$ & \\
\hline Poisson's ration $v=0.3$ & \\
\hline
\end{tabular}

the liquefiable soil with the relative density of $60 \%$ which was constructed by the dry deposition method, and then compacted to achieve the desired density. Then, the container was transferred to the shaking table to start the saturation process. Air was removed from the ground by the vacuum, and the soil was saturated using de-aired water. Detailed information on the construction process can be found in MEXT and NIED (2006), Tabata et al. (2007), and Motamed (2007).

An extensive range of instruments were employed to record numerous parameters during the shaking. The instruments comprised of strain gauges, accelerometers, laser and wire-type displacement transducers, earth pressure sensors, pore water pressure sensors, and inclinometers. In total, 883 channels of data were recorded for a better understanding of the behaviour of the model. In the pile group, six hollow steel piles were connected to the base with a pin connection by which the bending moment was made negligible, while being fixed at the top to the footing. A weight (12 tons) was mounted on the footing to reproduce the inertial effect of a superstructure. Moreover, a sheet pile was used as a quay wall to trigger the liquefaction-induced lateral spreading. Table 2 provides the detailed information about material properties of the pile foundation and the sheet pile quay wall.

\section{LARGE-SCALE TEST RESULTS}

The large-scale model was shaken under a two-dimensional input motion: horizontal and vertical components. The acceleration time histories were a scaled-down (80\%) version of the records obtained at JR Takatori station during the 1995 Kobe earthquake (Fig. 4). As shown in Fig. 4, the maximum amplitude of the horizontal component $(0.6 \mathrm{~g})$ was greater than the vertical acceleration $(0.23 \mathrm{~g})$. It is to be noted that horizontal ground displacement, inertial force, and lateral soil force are considered positive in the seaward direction, while acceleration is assumed to be positive in the landward direction (Fig. 5). Furthermore, it is worthy to mention here that since the

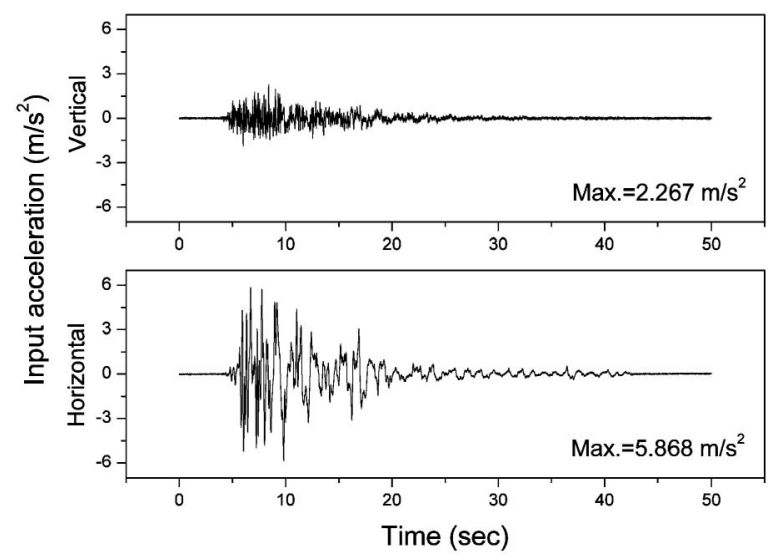

Fig. 4. Acceleration time histories of input motion

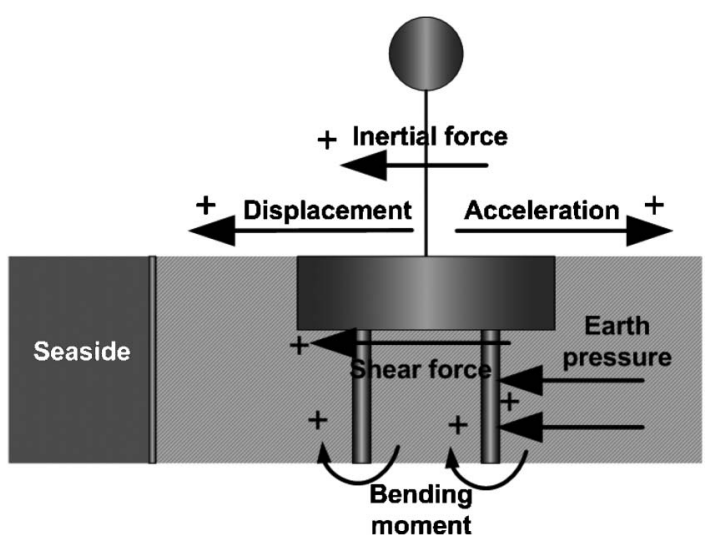

Fig. 5. Sign convention in this study

main objective of this paper concerns the monotonic component of the liquefaction-induced-lateral force of the soil, the cyclic component of the recorded parameters are mainly discarded herein after a filtering process. In the following sections, some of the results of this large scale test are presented.

\section{Lateral Soil Displacement}

During the shaking, extensive liquefaction occurred in the model ground; as a result, liquefaction-induced large ground deformation took place. Figure 6 illustrates the deformed shape of the model after the shaking, and arrows with numbers indicate the residual ground and pile displacements measured after the test. As can be seen, the sheet pile quay wall laterally moved about $1.1 \mathrm{~m}$ toward the sea (Fig. 7), the pile group horizontally displaced between $1.1 \mathrm{~m}$ to $1.4 \mathrm{~m}$ at the pile heads, and footing with superstructure tilted 20-degrees toward the land (Fig. 8). The directly observed surface ground displacements illustrate that the soil lateral deformation decreased as the distance from the quay wall increased toward the land (Fig. 6). This trend is same as the observations during past earthquakes (Ishihara et al., 1996, among others). In addition, the ground settled about $0.24 \mathrm{~m}$ on the landside, whereas heaved about $0.34 \mathrm{~m}$ on the seaside (Fig. 6). 

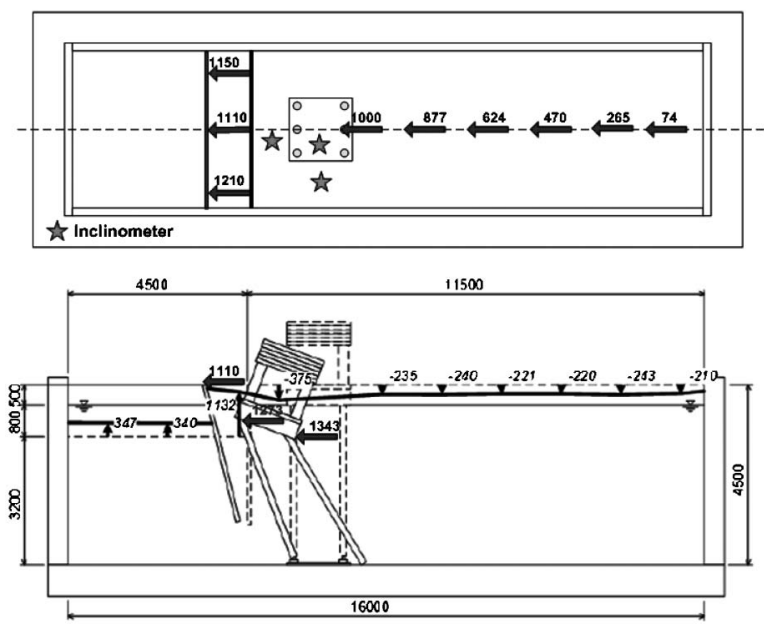

Fig. 6. Deformed shape of model after shaking and residual displacement values (units: $\mathrm{mm}$ ) (modified from MEXT and NIED, 2006; Tabata et al. 2007)

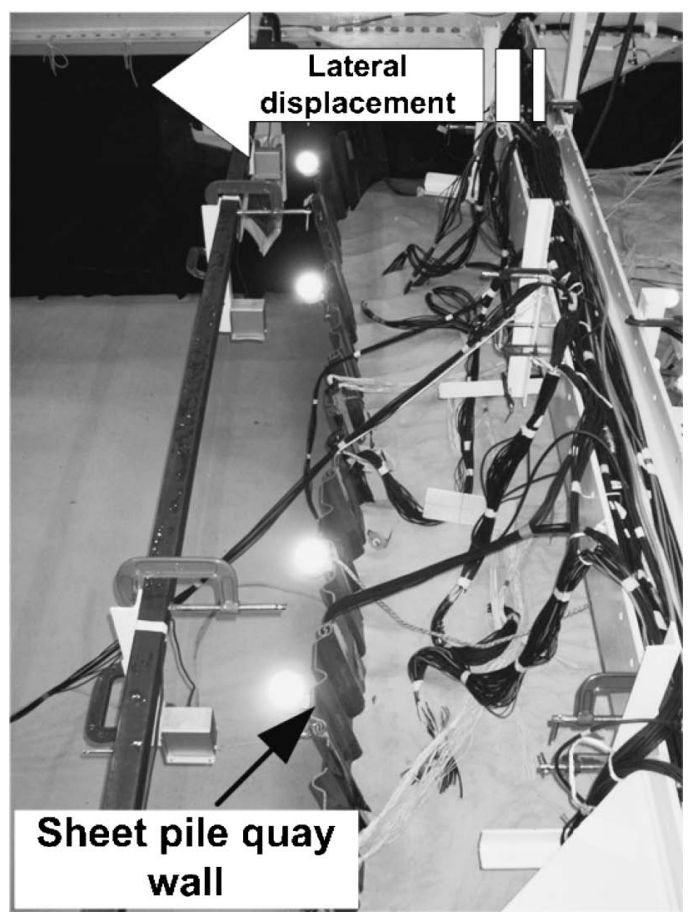

Fig. 7. Lateral displacement of sheet pile quay wall seaward

In order to record the time history of lateral soil displacements, inclinometers were installed (Fig. 9) at three points: behind the quay wall (Inclinometer A), inside the pile group (Inclinometer B), and beside the pile group (Inclinometer C). At each point, the inclinometer recorded the time history of lateral soil displacement at 13 different depths. Figures 10 to 12 demonstrate the time histories and the profiles of the soil displacement at three abovementioned points. Figures 10(a) to 12(a) present the time histories of lateral soil deformation at selected depths, and Figs. 10(b) to 12(b) illustrate the profiles of the lateral soil movement at different time steps. The results indicate that the maximum soil displacement be-

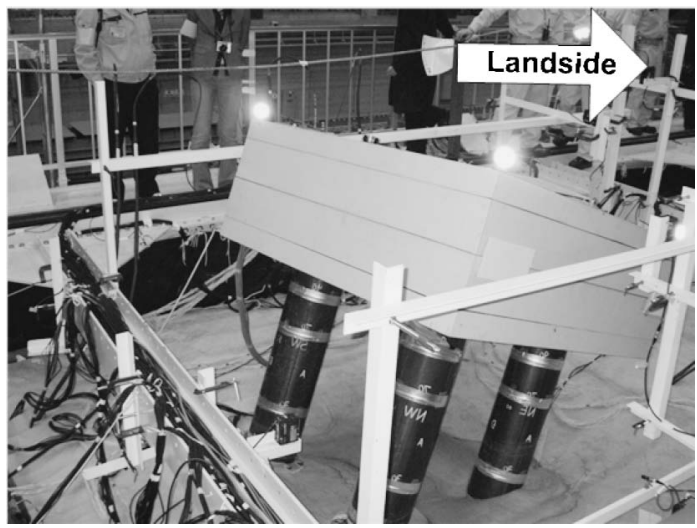

Fig. 8. Tilting of superstructure landward

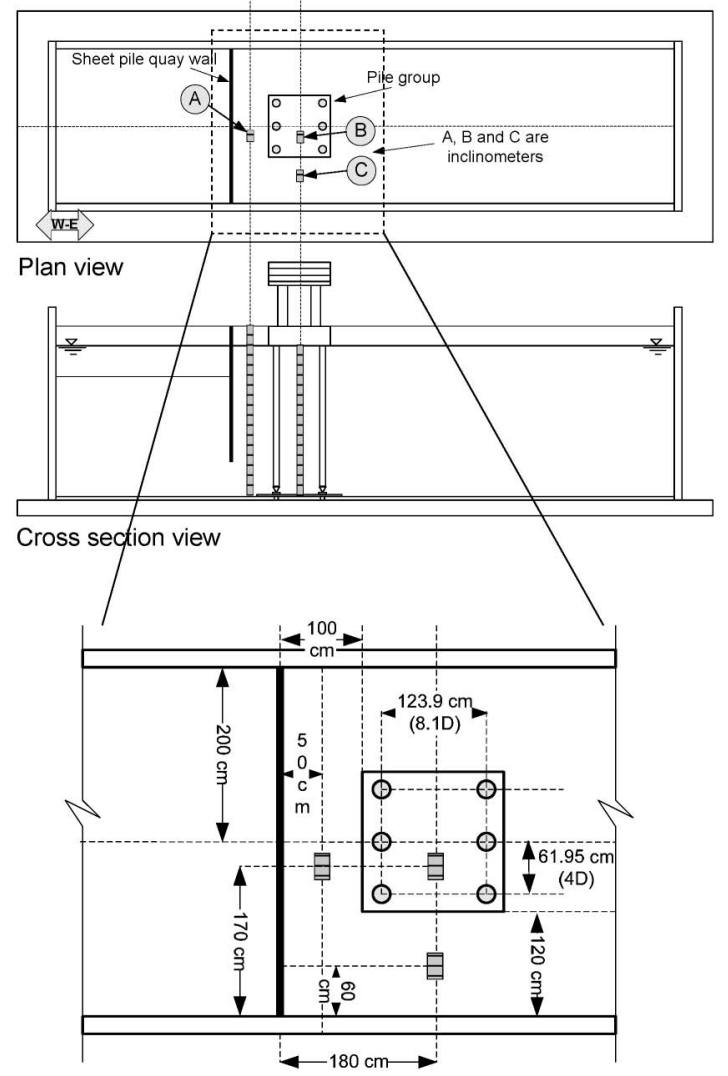

Fig. 9. Position of inclinometers in model to record lateral soil displacement

hind the quay wall was $89 \mathrm{~cm}$ which was greater than the soil displacement beside the pile group $(78 \mathrm{~cm})$. However, the soil displacement inside the pile group (Fig. 11) was unexpectedly large $(136 \mathrm{~cm})$. This contradiction was caused by the tilting footing which hit the Inclinometer B inside the pile group. A comparison between the time histories of the lateral soil deformation at the depth of 40 $\mathrm{cm}$ is depicted in Fig. 13, illustrating the error in the Inclinometer B caused by the tilting footing. This figure clearly demonstrates that the Inclinometer B was hit by the footing at the time of 10.2 seconds. Figure 13 indicates that prior to the time of 10.2 seconds, soil displacement was the largest behind the quay wall and its magni- 


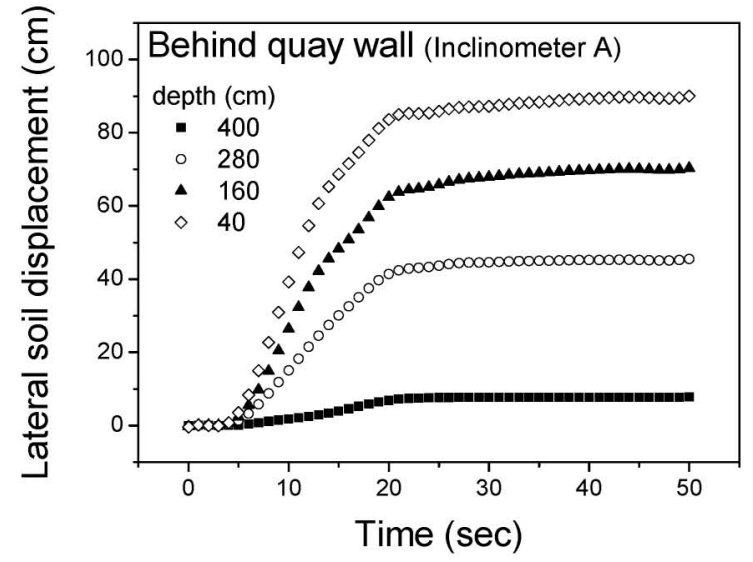

(a) Time history

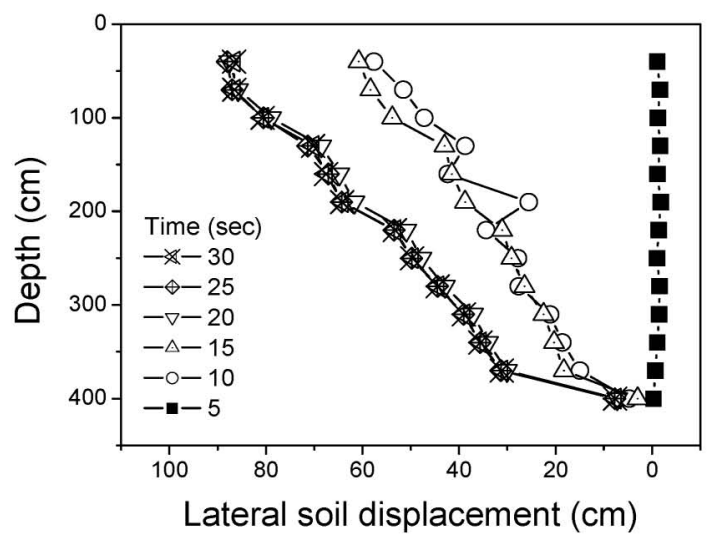

(b) Profile

Fig. 10. Lateral soil displacement by Inclinometer A -behind quay wall

tude was almost identical inside and beside the pile group, since the pile spacing in the group (4D and 8.1D) was large enough to prevent any group effect. However, the lateral soil deformation beside the pile group was slightly larger, representing the free ground movement.

Since the residual soil displacement at the ground surface was carefully measured after the shaking, a comparison between the inclinometer results and the observed soil displacements was made (Fig. 14). As is illustrated in this figure, inclinometers are able to measure the lateral soil displacement with a high accuracy, and this observation is in strong agreement with the previous findings by the first author (Motamed, 2007).

Since time history of the soil displacement was measured by inclinometers at different depths, it was possible to calculate the velocity of soil flow by the time derivative of displacement. For example, Fig. 15 displays time histories of the velocity of soil flow at different levels behind the quay wall and beside the pile group, respectively. As can be seen, the maximum velocity of soil flow was observed at the ground surface, and velocity behind the quay wall $(8.34 \mathrm{~cm} / \mathrm{s})$ was greater than that beside the pile group $(7.41 \mathrm{~cm} / \mathrm{s})$, being similar to the behaviour of soil displacement. The results in this section indicate that both displacement and velocity of the liquefied soil are

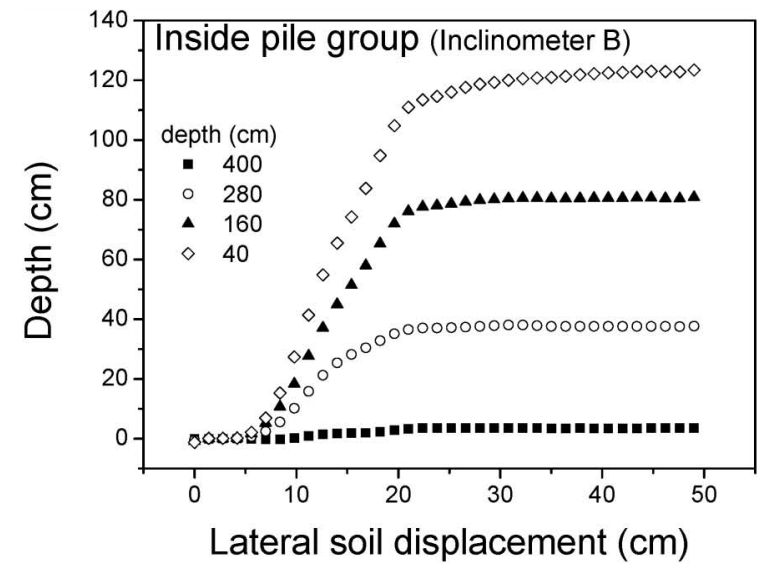

(a) Time history

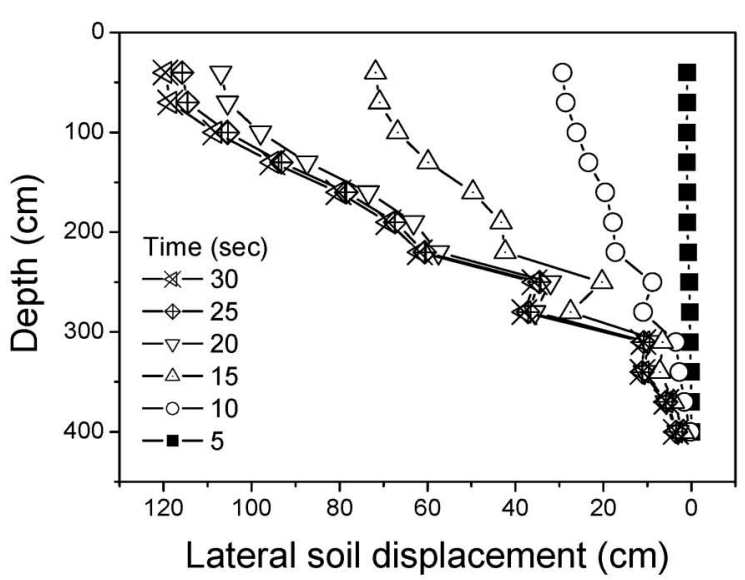

(b) Profile

Fig. 11. Lateral soil displacement by Inclinometer $B$-inside pile group

the largest immediately behind the quay wall and they decrease as the distance from the quay wall increases toward the landside.

\section{Bending Moment of Piles}

On average, 21 pairs of strain gauges were pasted on each pile to record bending strain in the direction parallel to the lateral soil flow. These data were then converted into bending moment using Eq. (1). It should be noted here that the piles were assumed to behave as an elastic linear material in this relation.

$$
M=\frac{E \varepsilon I}{y}
$$

in which

$M$ : Bending moment $(\mathrm{N} * \mathrm{~m})$

$E$ : Modulus of elasticity $\left(\mathrm{N} / \mathrm{m}^{2}\right)$

$\varepsilon$ : Bending strain recorded by strain gauges

I: Area moment of inertia $\left(\mathrm{m}^{4}\right)$

$y$ : Radius of pile (m).

For instance, Fig. 16 shows the recorded bending strain in Pile A1 at two different depths. The thick curve represents the monotonic component of the bending 


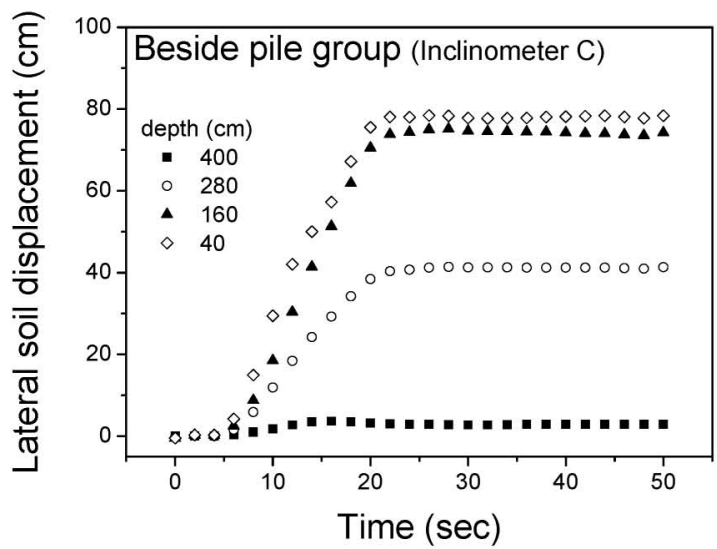

(a) Time history

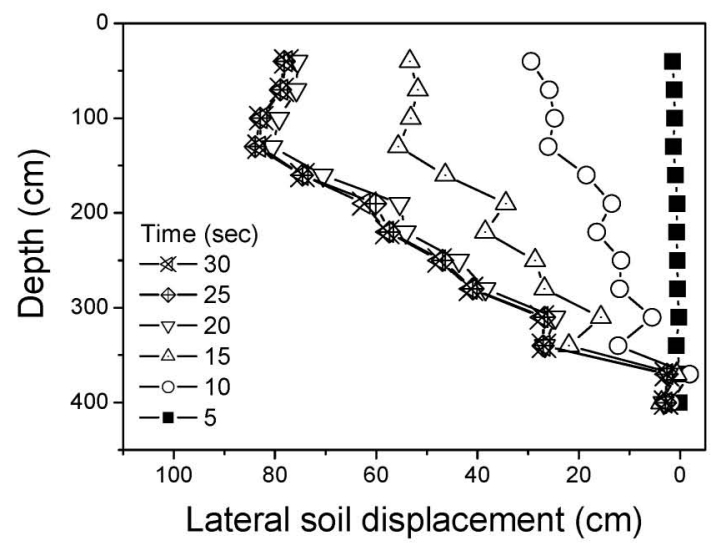

(b) Profile

Fig. 12. Lateral soil displacement by Inclinometer $\mathrm{C}$-beside pile group

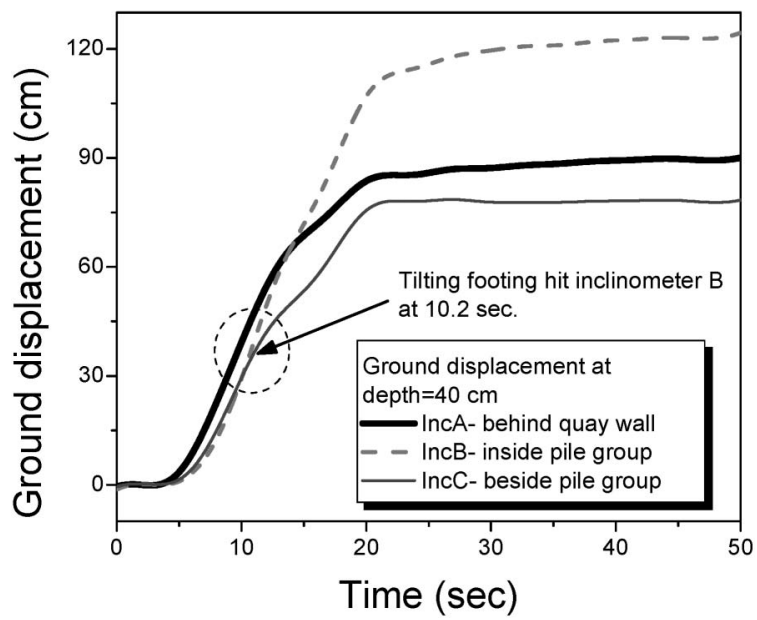

Fig. 13. Comparison between time histories of lateral soil displacement at depth $=40 \mathrm{~cm}$ recorded by inclinometers

strain which was obtained by filtering out the cyclic component. Then, the profiles of the monotonic component of the bending strain were prepared and some of the results are depicted in Fig. 17. As can be seen in this figure, large negative bending strain developed at the pile heads, while large positive bending strain was attained at

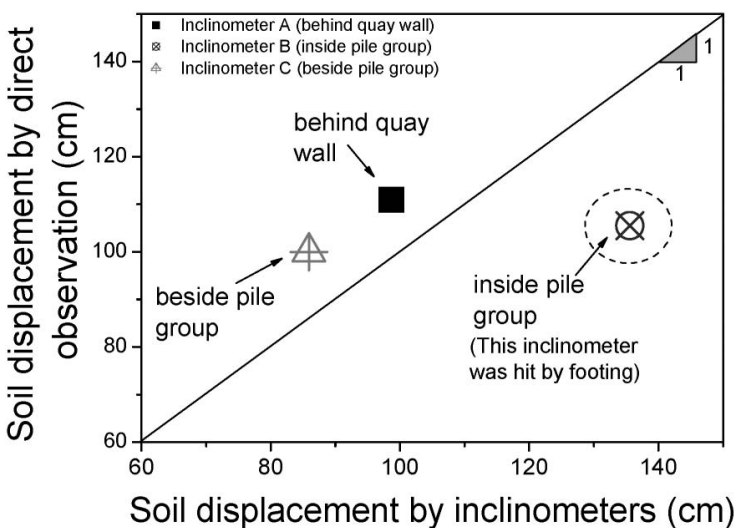

Fig. 14. Comparison between residual lateral soil displacement at ground surface recorded by inclinometers and direct observation

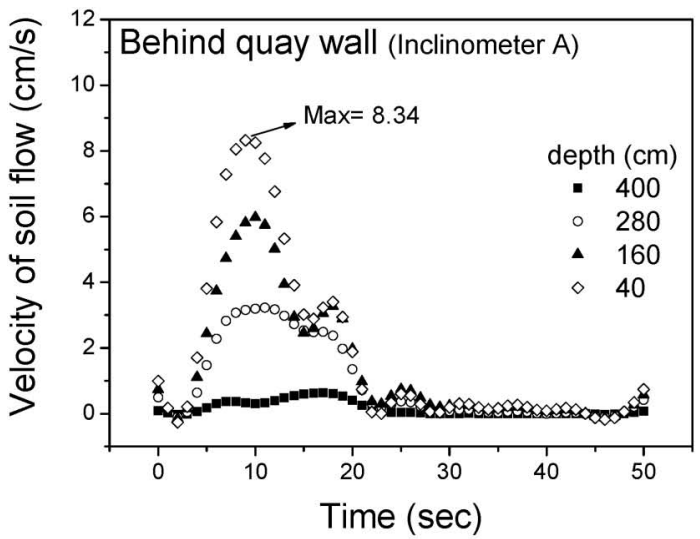

(a) Behind quay wall

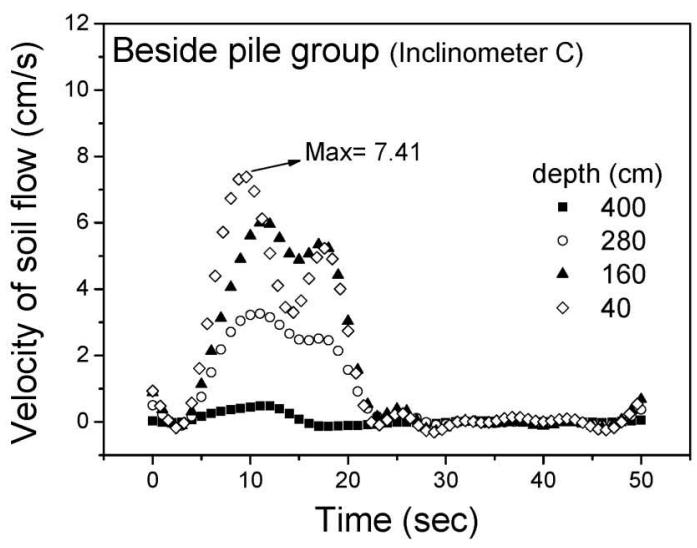

(b) Beside pile group

Fig. 15. Time histories of velocity of soil flow at different depths

the middle height of the piles. These observations are consistent with the plastic deformation in the piles, since all the piles yielded at the head (Fig. 18(a)), and the front row piles buckled at their middle height (Fig. 18(b)). It is noteworthy here that due to the yielding at the pile heads, some of the strain gauge cables were disconnected mainly at shallow depth and an example is displayed in Fig. 19. This disconnection caused some difficulties in assessing the lateral and shear forces from bending strain data 


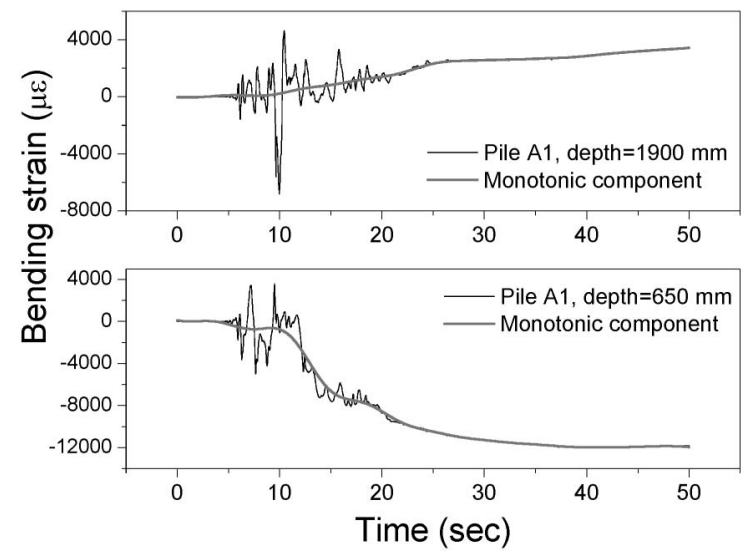

Fig. 16. Time histories of recorded bending strain by strain gauges at different depths together with monotonic component

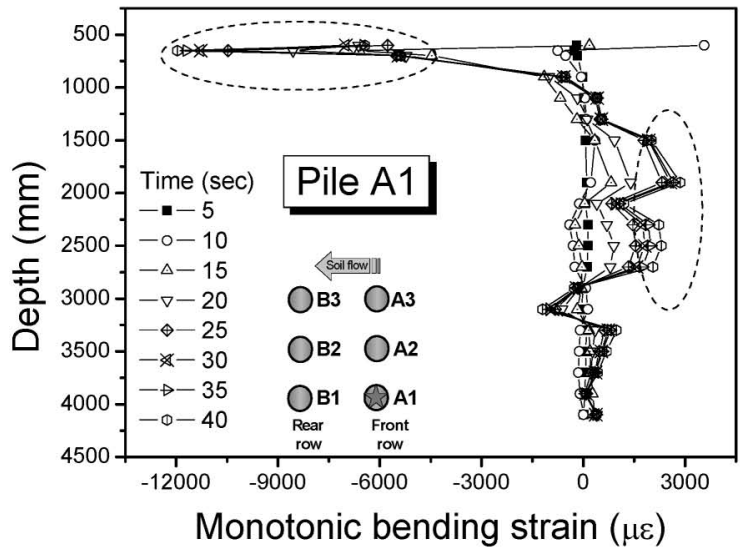

(a) Pile $\mathrm{A} 1$ in front row

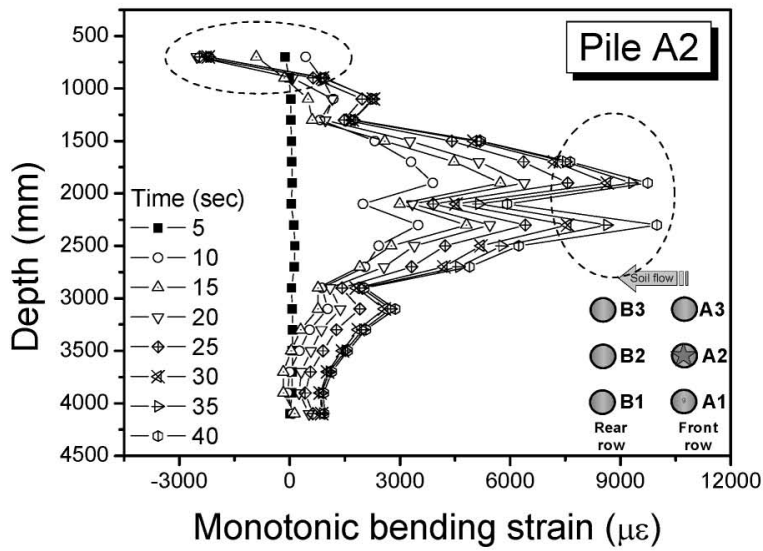

(b) Pile A2 in front row

Fig. 17. Profiles of monotonic component of bending strain in piles at different time steps

along the piles.

\section{Pore Water Pressure}

More than 200 pore water pressure (PWP) sensors were embedded in the model ground to record the generation of excess pore water pressure and monitor the extent of liquefaction state in the soil. Figure 20 schematically illustrates the position of the PWP sensors inside the

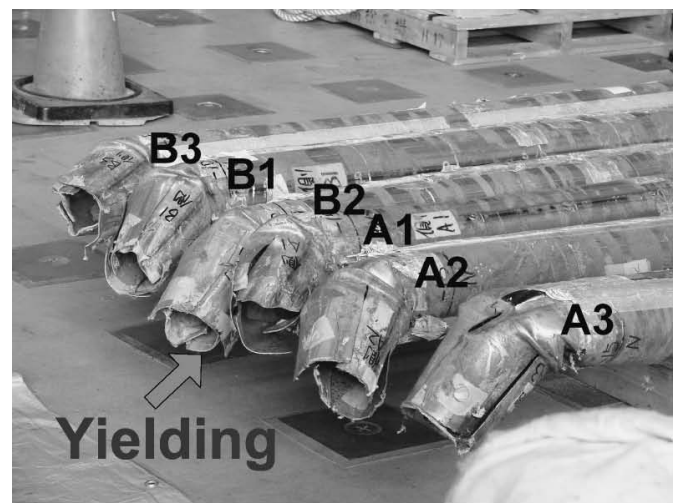

(a) Yielding at pile heads

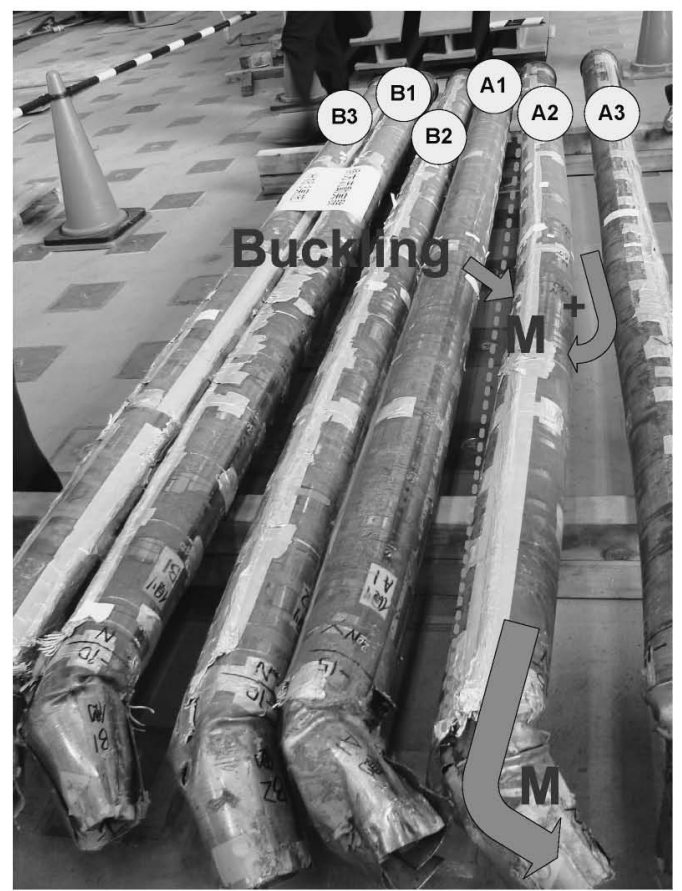

(b) Buckling at middle of piles

Fig. 18. Photos of damages to the piles

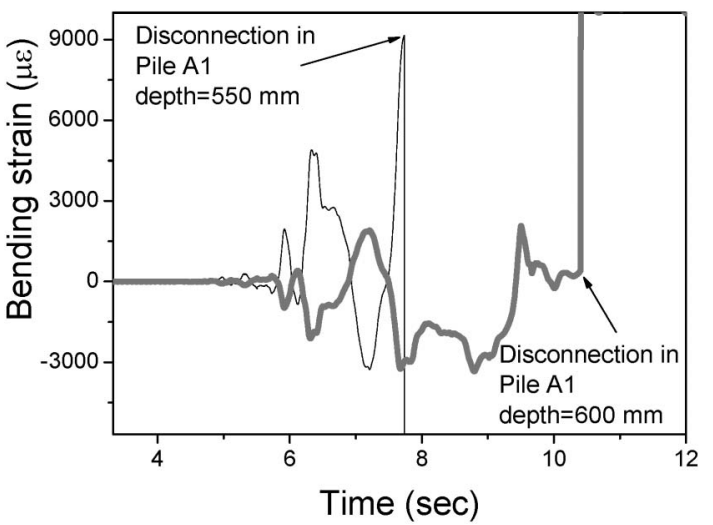

Fig. 19. Time histories of disconnected strain gauges in Pile A1

model ground. For instance, Fig. 21 presents the recorded PWP data on the landside (Line $\mathrm{E}$ and F) at three different depths $(600,1700,3300 \mathrm{~mm})$. As can be seen in 
(A) (B) (C) (D) (E)
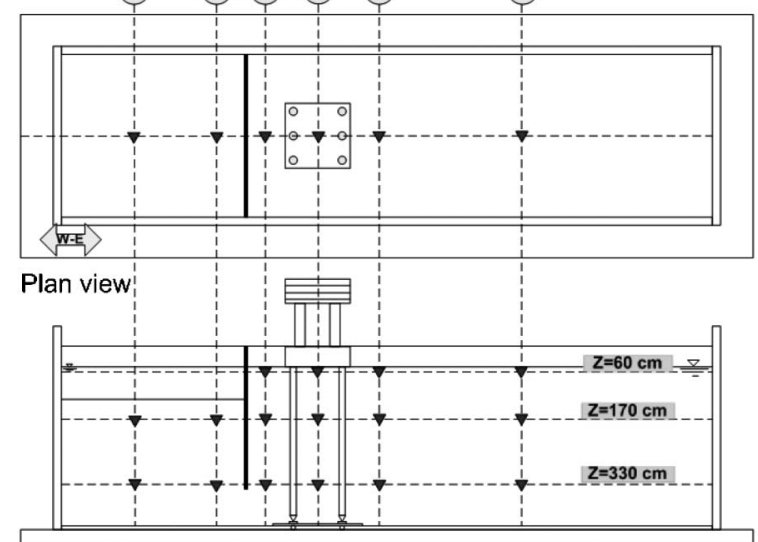

Cross section view

Fig. 20. Position of pore water pressure sensors inside ground at three different depths $(60 \mathrm{~cm}, 170 \mathrm{~cm}, 330 \mathrm{~cm})$
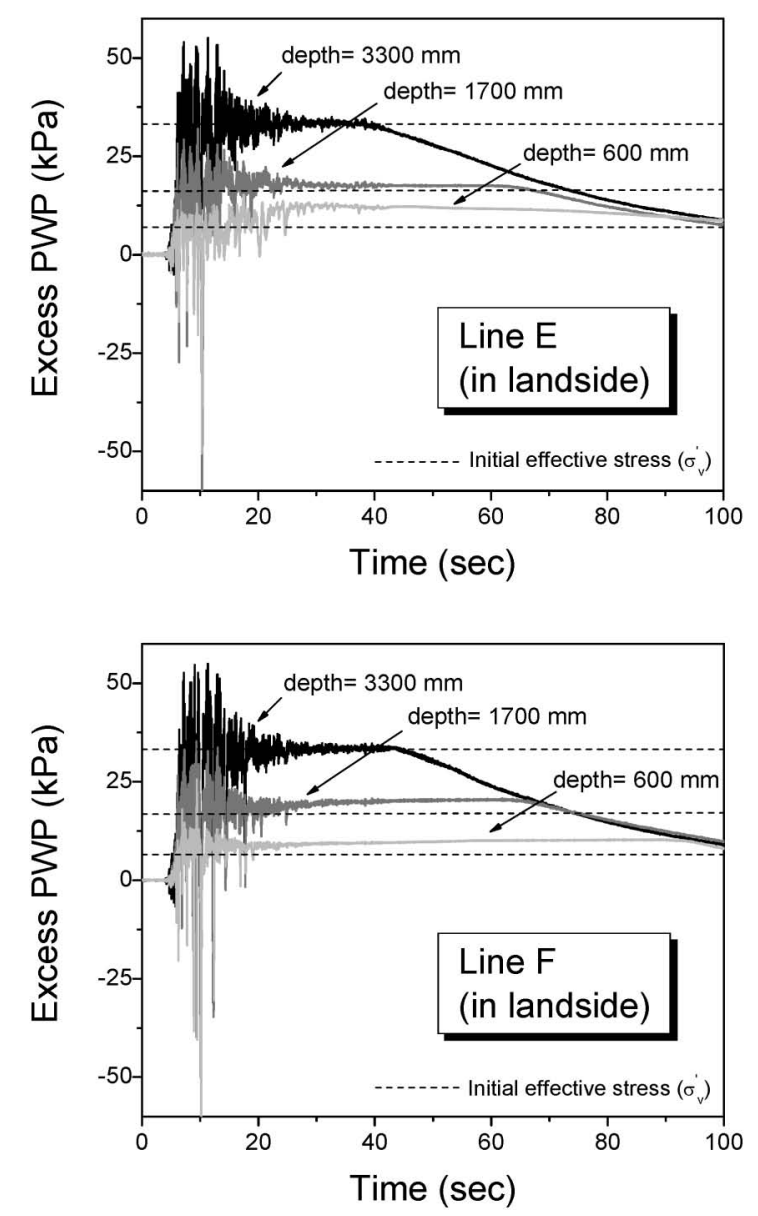

Fig. 21. Time histories of recorded excess pore water pressure inside ground

this figure, the liquefaction state in the ground was achieved at the early stage of the shaking as a consequence of experiencing several pronounced peaks in the input motion (Fig. 4). Furthermore, the PWP records at shallow depth exhibited few profound drops at the time of around 10 seconds which seem to be a result of exten- sive dilation in the liquefied soil. As shown in Figs. 10(a) to 12(a), liquefied soil experienced large displacements around this time, and Fig. 15 confirms that the maximum velocity of soil flow occurred at this time. In addition, excess PWP values larger than initial effective vertical stress were recorded, since the sensors were sunk into the ground during the liquefaction state.

Furthermore, several PWP sensors were pasted on both front (landward) and back (seaward) sides of each individual pile at different depths, and example records for the Pile B2 are given in Fig. 22 at the depths of 900, 2100 , and $3700 \mathrm{~mm}$ in which the fluctuation of PWP records was thoroughly investigated at two different phases:

a) Before the onset of lateral spreading (Fig. 22(b))

b) After the onset of lateral spreading (Fig. 22(c)) As can be seen from the records in Fig. 22, both front and back side PWP records are mainly in phase, and the deep depths records (2100 and $3700 \mathrm{~mm}$ ) are almost identical during the early stage of excess PWP built up (Fig. 22(b)). Some differences in the records at shallow depth $(900 \mathrm{~mm})$ were probably caused by the pile displacement. While, the dissimilarity of the time history amplitudes during the lateral spreading (Fig. 22(c)) is attributed to the inclination of the piles and the consequent changes in the overburden pressure of the soil (Fig. 6). There is a discussion saying that cavity effect in PWP records in the back side of a pile foundation is developed during the lateral spreading, indicating tensile stress state. Although the authors investigated the records at all depths around the piles, the results appear to decline this idea for the case of this experiment. The representative records in Fig. 22 illustrate that there was no significant drop in the PWP data except few at the shallow depth at the time of $10 \mathrm{sec}-$ onds which would be accounted for the extensive dilation in the liquefied soil.

\section{DIRECT MEASUREMENT OF LATERAL FORCE OF LIQUEFIED SOIL BY EARTH PRESSURE SENSORS}

In order to directly measure the lateral force of the liquefied soil, earth pressure (EP) sensors were attached to the piles. The earth pressure sensors had a circular shape with the diameter of $6 \mathrm{~mm}$ which were glued on the piles at predetermined points. Since the diameter of the sensor $(6 \mathrm{~mm})$ was much smaller than the diameter of the piles $(152.4 \mathrm{~mm})$, it could be easily attached to the curved surface of the piles. Figure 23 illustrates two different configurations of the EP sensors whose results are presented in this paper: partially and fully instrumented. These sensors were installed along the piles at different depths. Figure 24 displays the EP sensor before pasting on the pile.

Earth pressure was recorded mainly at two opposite sides of each pile (partially instrumented, Fig. 23(a)) and in some levels at six points on the pile circumference (fully instrumented, Fig. 23(b)). Figure 25 presents the time histories of the earth pressure at four points on the circumference of the Pile B2 at the depth of $2100 \mathrm{~mm}$. As 


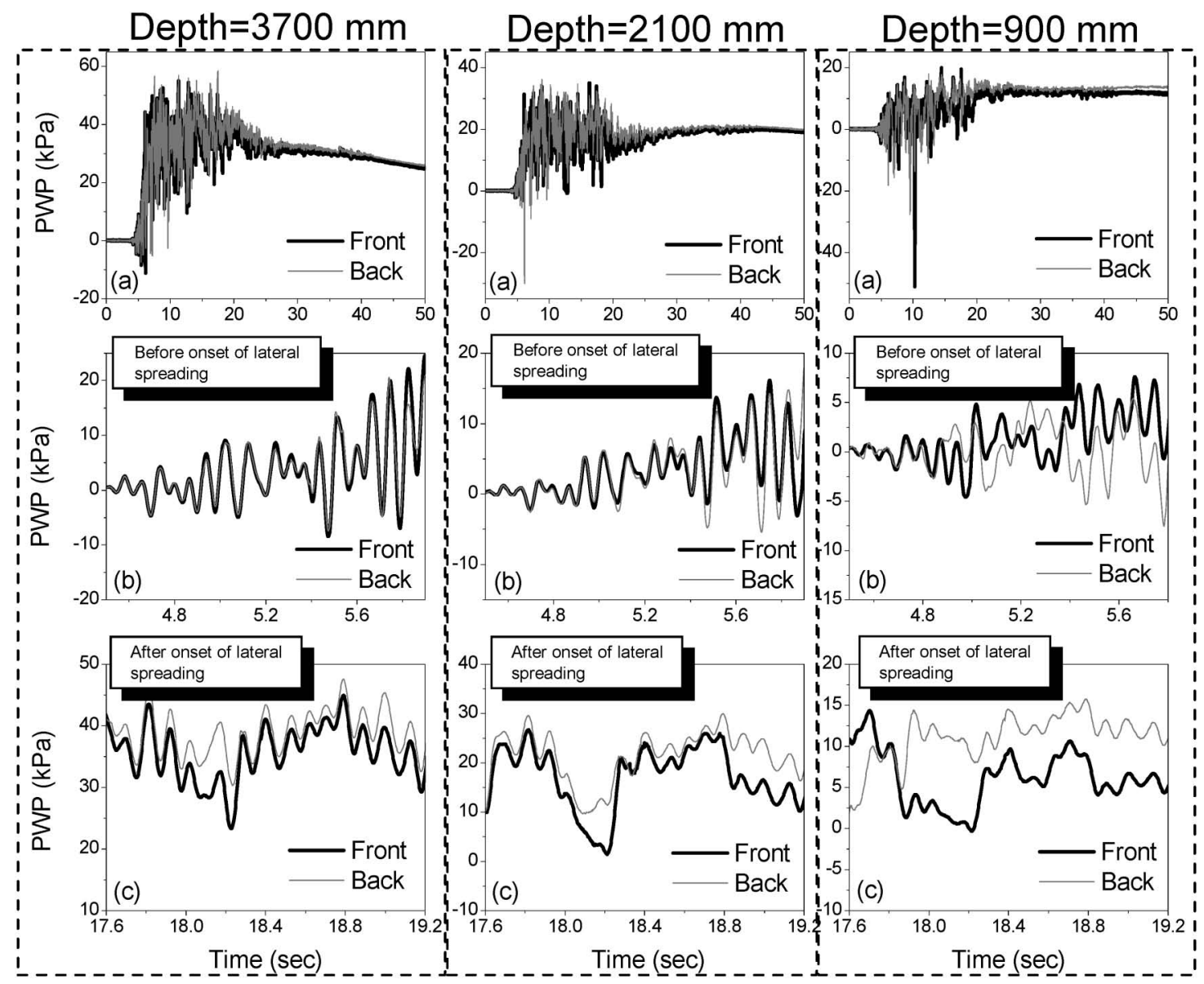

Fig. 22. Time histories of recorded excess pore water pressure at both front (landward) and back (seaward) sides of Pile B2 - depth $=900,2100$, and $3700 \mathrm{~mm}$

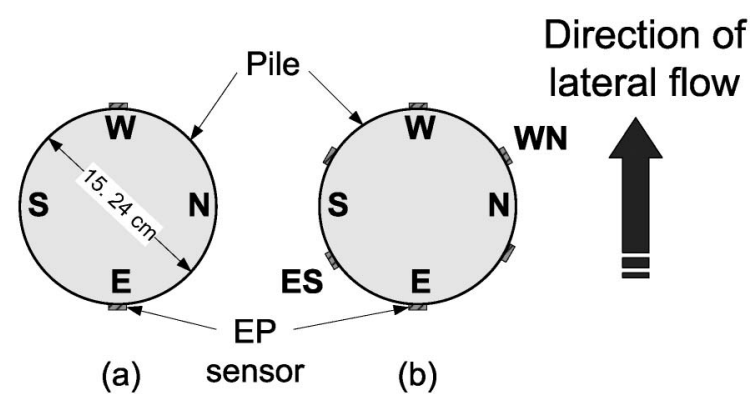

Fig. 23. Two different configurations of earth pressure sensors attached to piles: (a) partially instrumented and (b) fully instrumented cross sections $(E=$ East, $\mathbf{W}=$ West, $\mathbf{N}=$ North, $\mathrm{S}=$ South $)(\mathrm{mo}-$ dified from MEXT and NIED, 2006)

can be seen, East (E) and West (W) components display larger earth pressures than other two records as a result of large lateral displacement of the liquefied soil in the E-W direction.

Since the main objective of this paper was to study the lateral force of the liquefied soil on the piles, this lateral force was calculated using Eq. (2).

Lateral force on pile $=\left(\right.$ Pressure $_{\mathrm{E}}-$ Pressure $\left._{\mathrm{W}}\right)$ $\times$ pile diameter

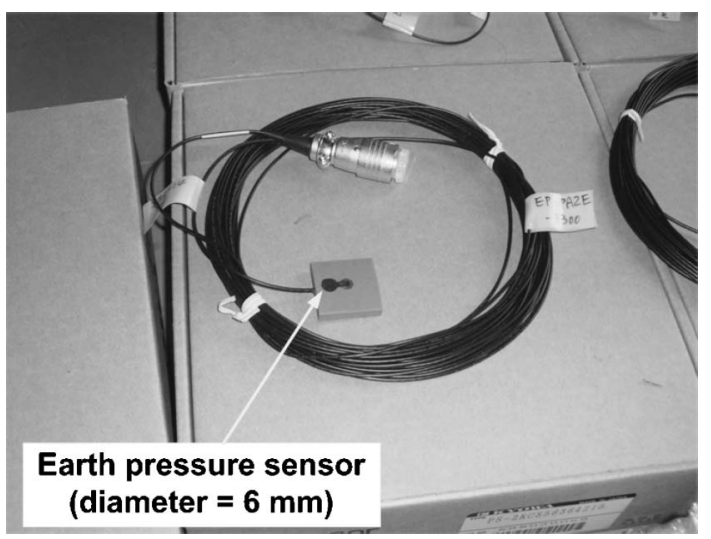

Fig. 24. Earth pressure sensor before installation

in which Pressure E $_{\mathrm{E}}$ and Pressure ${ }_{\mathrm{W}}$ stand for the recorded earth pressures by the EP sensors in front (landward) and back (seaward) sides of a pile, respectively. An example of the resulted lateral force of the liquefied soil is given in Fig. 26 in which the time histories of this lateral force at four different depths are depicted for the case of Pile B2.

As was shown in Fig. 6, the piles tilted during the shaking; as a result, the EP records were affected by the overburden pressure of the soil. Therefore, the EP records are 


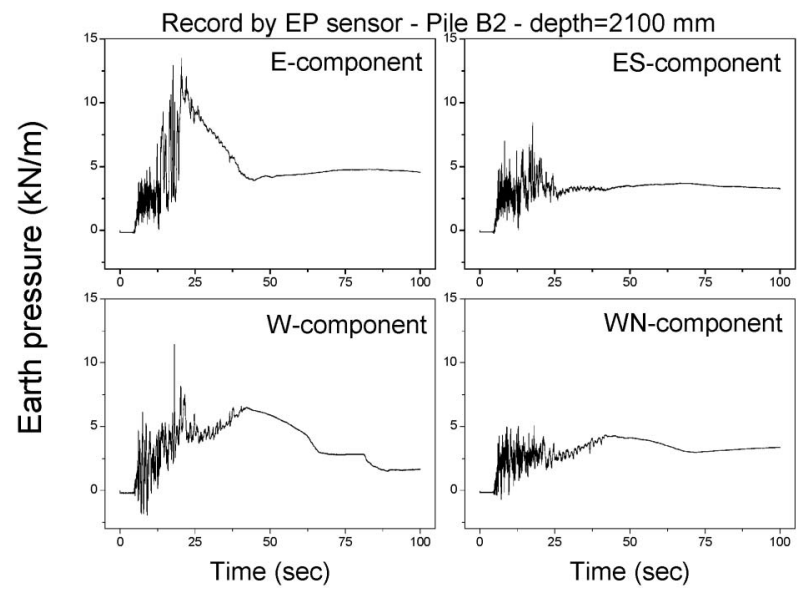

Fig. 25. Time histories of earth pressures recorded by EP sensors on circumference of Pile B2 at depth $=2100 \mathrm{~mm}$

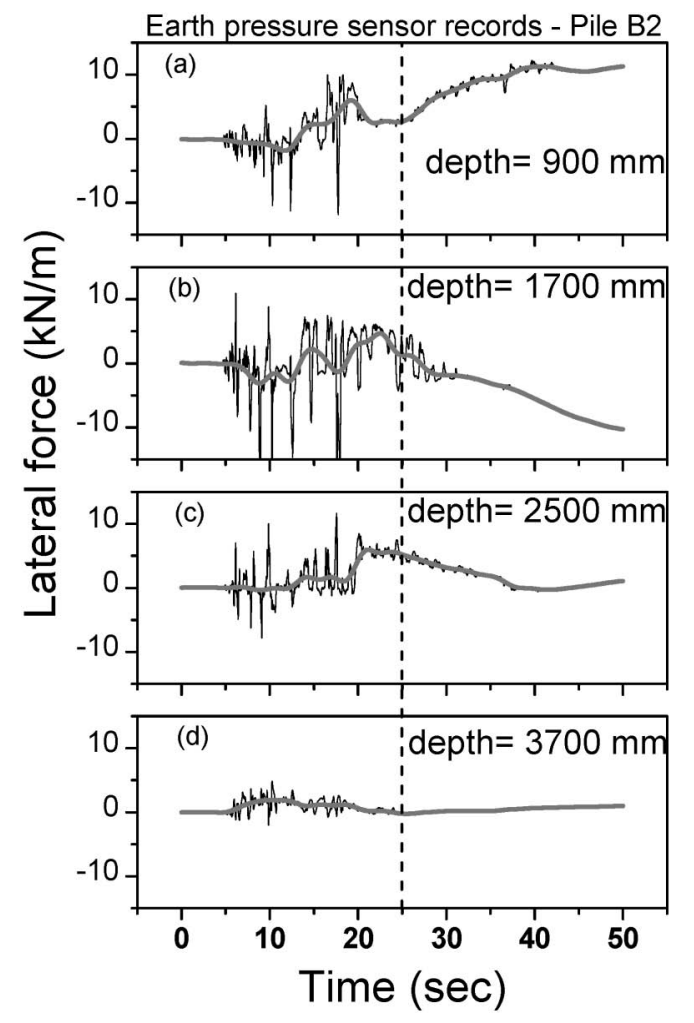

Fig. 26. Time histories of lateral forces recorded by EP sensors at different depths together with monotonic components-Pile B2

reliable prior to the time of 25 seconds at which a large monotonic component appears in the records (Figs. 26 and 27). Next, the monotonic components of the lateral forces were obtained after filtering out the cyclic components and are shown by the thick curves in Fig. 26. Based on the illustration in Fig. 23, it is worthy to note that the positive lateral force demonstrates that the pile is pushed by the lateral flow of the liquefied soil; while, the negative value means that the pile pushes the soil landward. Hence, the positive monotonic lateral forces at different depths during the shaking (Fig. 26) indicate remarkable lateral forces exerted by the liquefied soil during the liq-
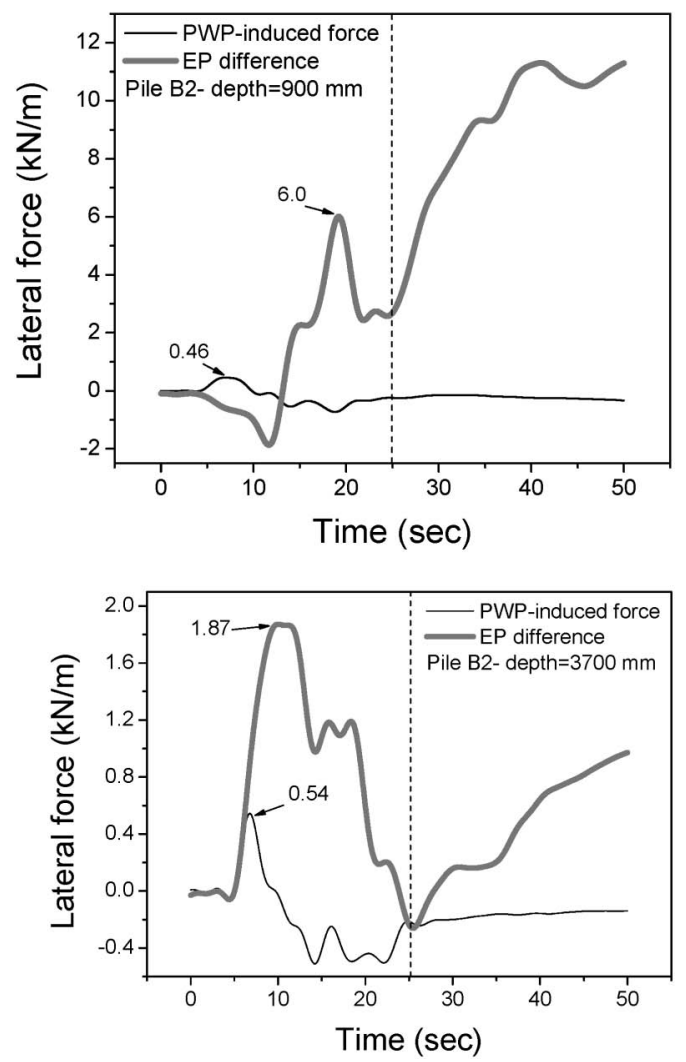

Fig. 27. Comparison between time histories of PWP-induced lateral force and records by $E P$ sensors-Pile $B 2$, depths $=900$ and 3700 mm

uefaction-induced large ground displacement.

There is an opposing opinion saying that different excess PWP in front and behind a pile generates a net lateral force, and this differential pore pressure is the consequence of compressive and dilative stress conditions on the respective sides. In order to examine this idea, the PWP-induced lateral force was evaluated using Eq. (3).

$$
\begin{aligned}
\mathrm{PWP} \text {-induced lateral force }= & \left(\mathrm{PWP}_{\mathrm{E}}-\mathrm{PWP}_{\mathrm{W}}\right) \\
& \times \text { pile diameter }
\end{aligned}
$$

in which $\mathrm{PWP}_{\mathrm{E}}$ and $\mathrm{PWP}_{\mathrm{W}}$ represent the recorded excess pore water pressure in front (landward) and behind (seaward) the piles, respectively. The time history of PWP-induced lateral forces at two depths are depicted in Fig. 27, and it is shown that the maximum value due to the PWP difference is considerably smaller than the lateral force recorded by the EP sensors. This observation was valid for both shallow and deep depths (900 and $3700 \mathrm{~mm}$ ). In order to compare the PWP-induced lateral forces and the EP-recorded forces, the maximum monotonic component of these two forces are presented in Fig. 28, and the results clearly indicate that the lateral force due to the PWP-difference is much smaller $(\sim 10 \%)$ than the EPmeasured forces. Hence, the contribution of PWP differences in the total lateral force seems to be insignificant.

In order to investigate the vertical distribution of the maximum lateral soil force along the piles, the monotonic component of the lateral force by the EP sensors was ob- 


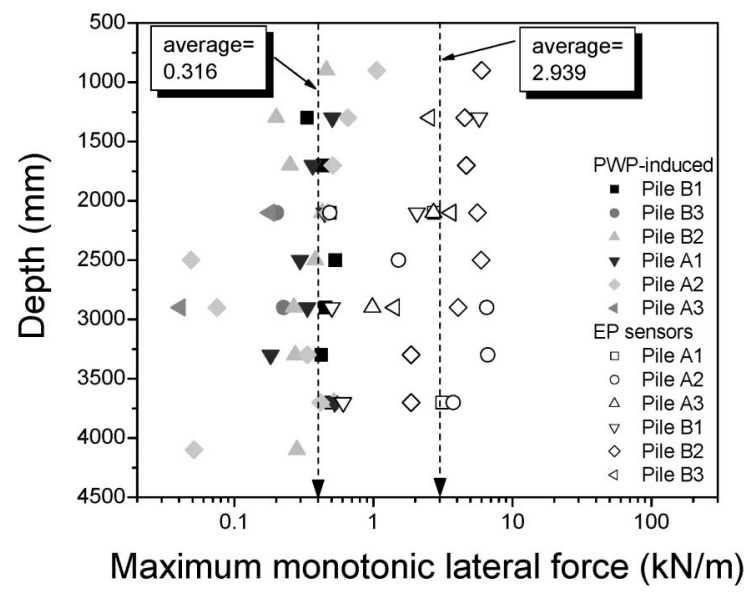

Fig. 28. Comparison between maximum monotonic component of lateral forces resulted from PWP differences and measured by EP sensors in piles
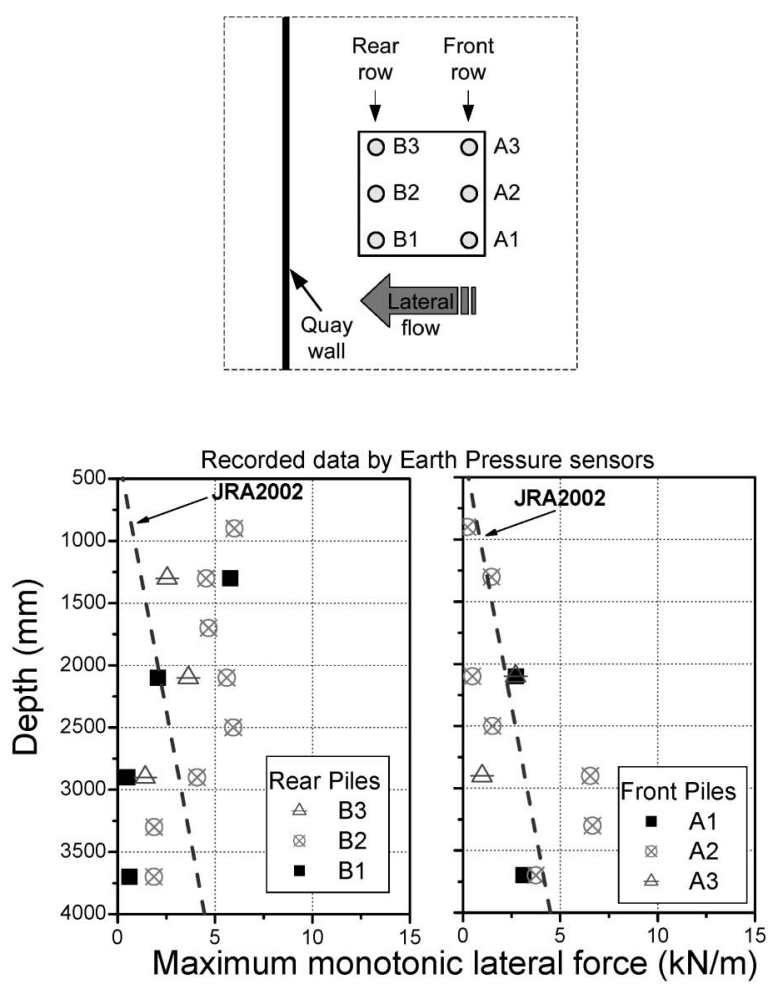

Fig. 29. Profiles of maximum monotonic component of lateral force on piles from EP sensors and recommended value by JRA2002 design code

tained for all piles prior to the time of 25 seconds at different depths and the maximum values were selected to plot the profiles of the liquefaction-induced lateral force. These profiles are presented in Fig. 29 for both front (far from the quay wall) and rear (close to the quay wall) row piles. There are some important findings which can be drawn from these profiles. Previously, Figs. 14 and 15 showed that both soil displacement and velocity of the soil flow behind the quay wall were the greatest and their amplitude reduced as distance from the quay wall increased landward. As a result, the recorded lateral force

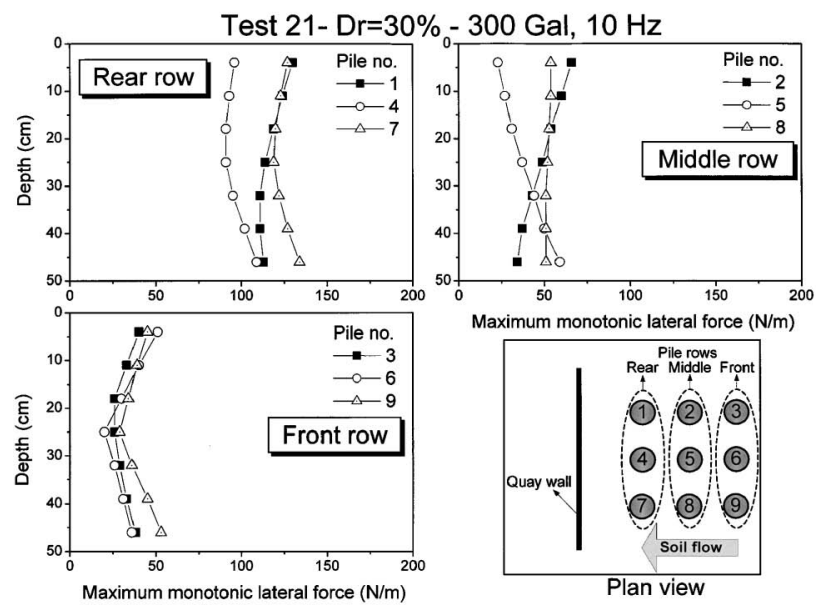

Fig. 30. Profiles of maximum monotonic component of lateral force in a $3 \times 3$ pile group - results of 1-G shaking table tests (Motamed, 2007)

in the rear row piles (Piles B1, B2, B3 which were close to the quay wall) were greater than those for the front row piles (Piles A1, A2, A3 which were far from the quay wall). This observation is consistent with the 1 -g shaking table model tests by the first author (see Fig. 30 for an instance) where details and results can be found in Motamed (2007).

It is noteworthy that the differences between the profiles for rear and front rows might be due to the breakage at the bottom connection in the front row piles during the shaking (Fig. 6). Since it was not possible to estimate the time of disconnection, the earth pressure records in the front row piles were discarded from further investigation.

Then, attempts were made to evaluate the efficiency of the JRA2002 design code (Japan Road Association, 2002) to estimate the lateral force of liquefaction-induced large ground displacement exerted on the piles. This design code recommends $30 \%$ of the total overburden pressure (total stress) to be multiplied by the outermost width of the group pile to obtain the lateral force per unit depth exerted by the flow of liquefied soil. In addition, for the design purpose, it is assumed this total lateral force is equally distributed among the piles in the group. For comparison, the recommended lateral force by the JRA 2002 is included in Fig. 29 by the dashed lines, and as can be seen, the design code underestimates this force, and this underestimation is more pronounced for the rear row piles.

As the data of EP sensors were not available at all depths, it was a very difficult task to propose the vertical distribution for the lateral force of the liquefied soil. Nevertheless, the available profiles, especially for the case of rear row piles, would recommend that the suggested vertical distribution by the JRA2002 (Fig. 29) appear to be inappropriate. In this regard, it is worthy to note that an extensive series of 1 -g shaking table model tests by the first author on the pile groups behind a sheet pile quay wall suggested that it would be reasonable to uniformly idealize the distribution of lateral force of the liquefied 
soil exerted on the piles and an example of the results is displayed in Fig. 30 (Motamed, 2007). This finding was concluded after considering several parameters such as amplitude, frequency and direction of input motion; density of ground; and pile head fixity.

\section{BACK-CALCULATION PROCEDURE}

Since an extensive number of strain gauges were attached to the piles, it was then possible to back calculate shear and lateral forces based on the theory of elastic beam. The method of back calculation has been successfully employed in several studies (Tokimatsu and Suzuki, 2004, among the others) to obtain shear and lateral forces, and deflection of piles. Therefore, it was attempted, in this study, to back calculate both shear and lateral forces in piles throughout the shaking. However, in contrast to the basic assumption of the elastic beam theory, plastic deformation happened in the piles (Fig. 18) which substantially made this study different from other studies. Therefore, the back-calculated parameters could be employed for analysis and further discussion up to the time of 6.2 seconds at which the plastic deformation initiated. This time, 6.2 seconds, was obtained based on a through investigation which is elaborated in the following subsection.

\section{Back-Calculated Lateral Force of Liquefied Sand}

An important objective of this large-scale experiment was to investigate the lateral force exerted on the piles by the flow of liquefied soil. Two different techniques were employed in this study to calculate this lateral force. The first method which was elaborated in the previous section (direct measurement by EP sensors) provided an invaluable reference to evaluate the efficiency and reliability of the second approach that was the back calculation from strain gauge records.

The lateral force was back calculated by the secondorder time derivatives of the bending moment along the piles (Eq. 4) using the finite difference method.

$$
\begin{aligned}
P(x) & =-\frac{d^{2} M}{d x^{2}} \\
& =-\frac{M(x+\Delta x)-2 M(x)+M(x-\Delta x)}{(\Delta x)^{2}}
\end{aligned}
$$

in which:

$x$ : Depth below ground surface $(\mathrm{m})$

$P$ : Lateral force of liquefied soil $(\mathrm{N} / \mathrm{m})$

$M$ : Bending moment from strain gauge records $(\mathrm{N} * \mathrm{~m})$. Figures 31 and 32 present the time histories of the backcalculated lateral force for two different cases. In the former figure, the back-calculated lateral force is depicted at the depth of $900 \mathrm{~mm}$ where a considerable plastic deformation occurred (close to yielding at the pile heads, see Fig. 18(a)). In contrast, the latter figure displays the back-calculated lateral force at the depth of $3700 \mathrm{~mm}$ where there was no noticeable plastic deflection in the pile.

In order to quantitatively determine the time at which

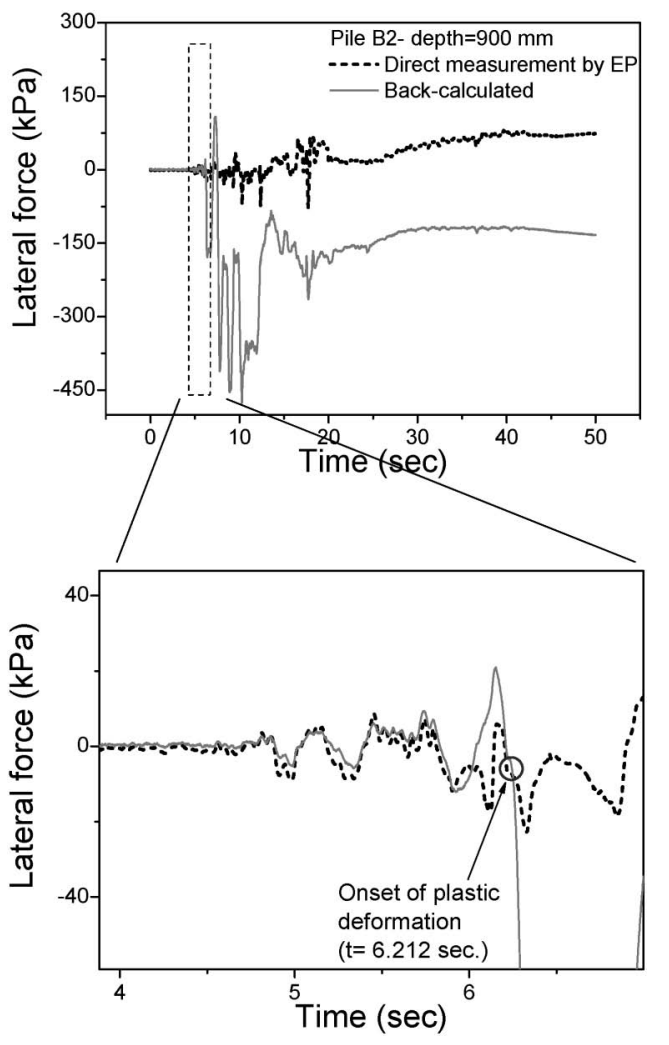

Fig. 31. Time histories of back-calculated and directly measured lateral forces in case of significantly observed plastic deformation in pile B2 - close to yielding at pile head

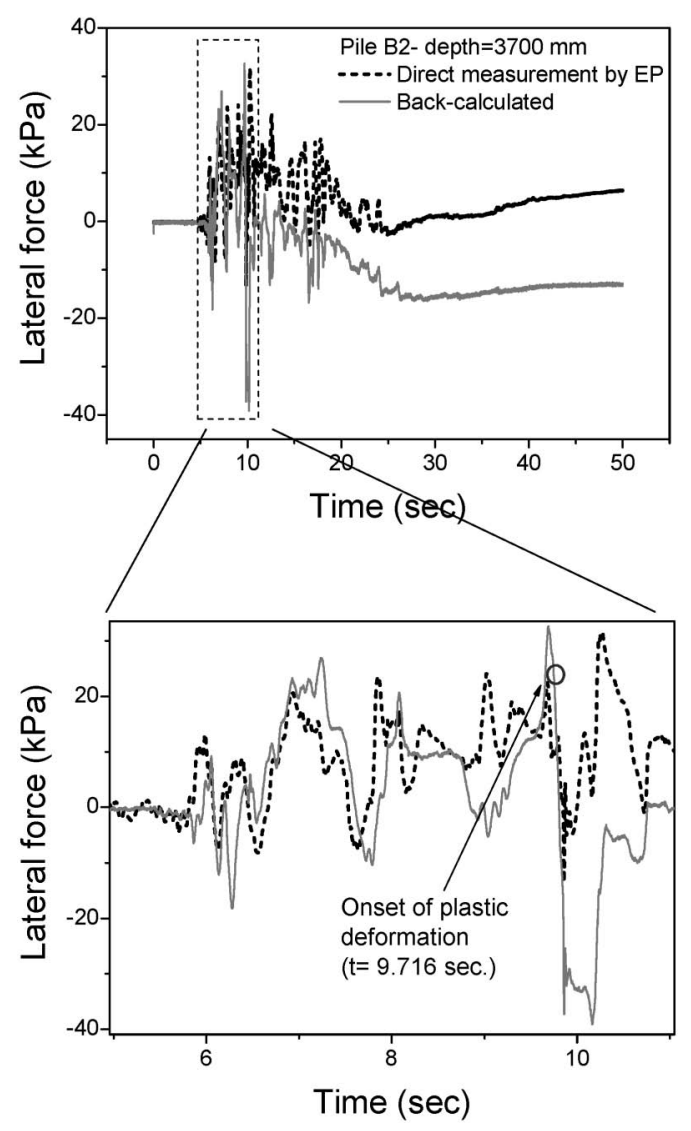

Fig. 32. Time histories of back-calculated and directly measured lateral forces in case of insignificant plastic deformation in pile B2 


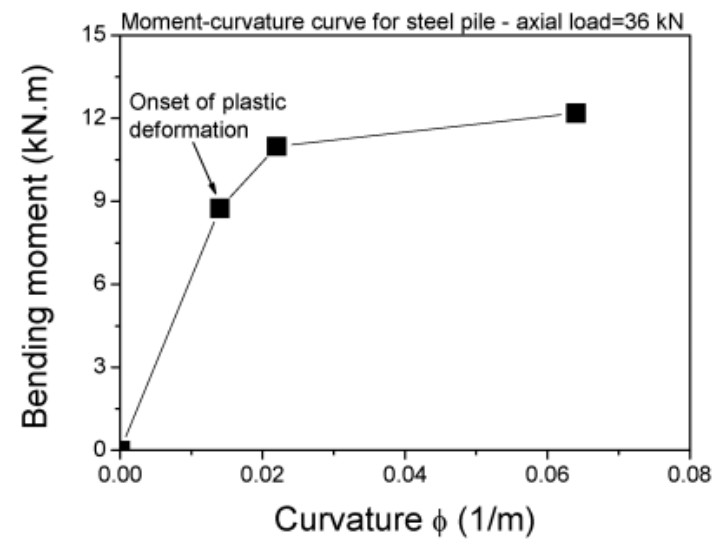

Fig. 33. Moment-curvature diagram for steel pile foundation undergoing axial load of $36 \mathrm{kN}$ (experimental model of pile behavior, after Fukutake, 2006)

the plastic deformation initiated, a careful investigation was performed on the bending moment records as follows. First, based on the material properties (Table 2) and the moment-curvature diagram of the pile foundation (Fig. 33), the bending moment corresponding to the onset of plastic deformation from which the pile response was no longer linearly elastic was determined. This typical bending moment was $8.74 \mathrm{kN} * \mathrm{~m}$ considering the axial load in each pile, i.e., $36 \mathrm{kN}$, based on the weight of the superstructure and the footing.

By knowing the bending moment related to the onset of plastic deformation, the time when the pile response initiated its nonlinear behaviour was established. Figure 34 illustrates an example of this process for two different depths. As can be seen, at the time of 6.212 seconds the plastic deformation started at the depth of $900 \mathrm{~mm}$, while it initiated at the time of 9.716 seconds at the depth of $3700 \mathrm{~mm}$. These two examples are marked in Figs. 31 and 32 and they are clearly able to quantitatively explain the limitations of the back-calculation procedure.

This procedure was repeated for all depths and the earliest time of the onset of plastic deformation in the piles was determined, i.e., time $=6.2$ seconds. Therefore, it apparently indicates that the back-calculated parameters are reliable up to the time of 6.2 seconds.

Moreover, the directly measured lateral forces by the EP sensors at the same depths are included in Figs. 31 and 32 for comparison (thick dotted curve). Comparison between the directly measured (Eq. (2)) and the back-calculated lateral forces (Eq. (4)) clearly reveals the following points.

- When the pile behaviour is still linearly elastic, there is an acceptable agreement between directly measured and back-calculated lateral forces. In other words, the back-calculation procedure based on the assumption of linearly elastic behaviour of the material could be utilized until the plastic deformation starts.

- After plastic deformation in piles, back-calculated method overestimates the lateral force. In Fig. 31, discrepancy in the recorded and back-calculated lateral forces started at the time of 6.212 seconds when the pile

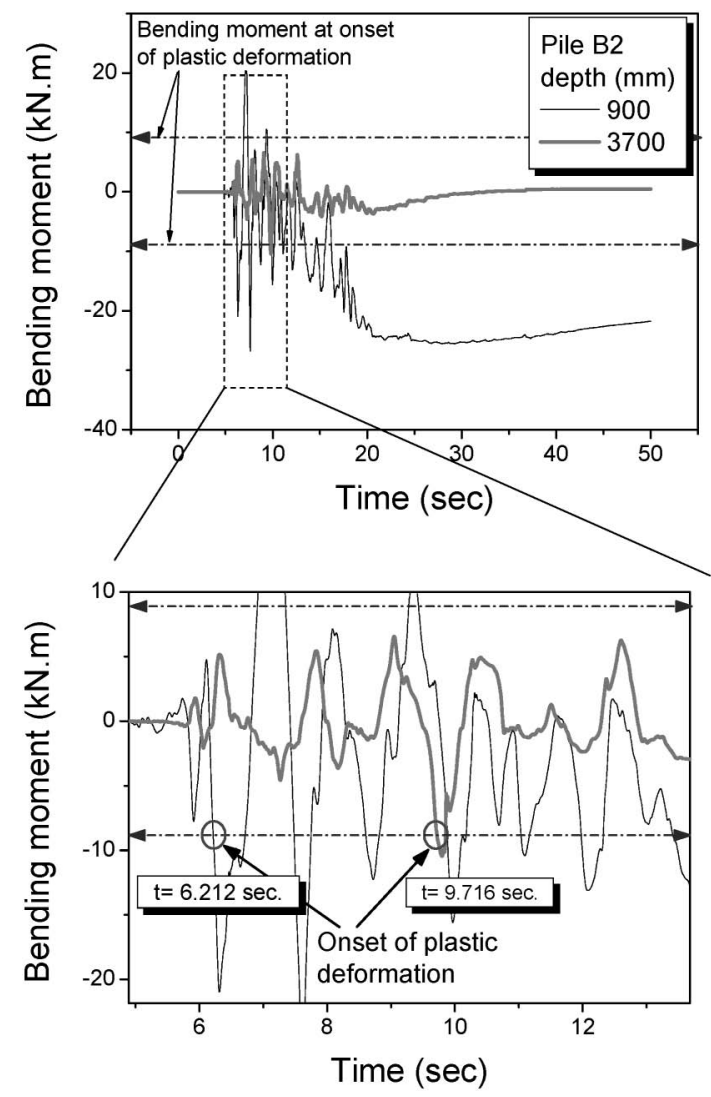

Fig. 34. Time histories of bending moment in Pile B2 recorded by strain gauges at two depths

response was no longer linearly elastic.

\section{Back-Calculated Shear Force at Pile Heads}

Shear force in piles was then calculated by the derivative of the bending moment along the piles (Eq. (5)) using the finite difference method.

$$
V(x)=\frac{d M}{d x}=\frac{M(x+\Delta x)-M(x)}{\Delta x}
$$

in which:

$x$ : Depth below ground surface (m)

$V$ : Shear force in pile $(\mathrm{N})$

$M$ : Bending moment from strain gauge records $(\mathrm{N} * \mathrm{~m})$. Figure 35 presents time histories of the shear force at the pile heads. However, the shear force value after the time of 6.2 seconds is not reliable because of the intensive plastic deformation (yielding) at the pile heads (Fig. 18(a)), hence it can not be attributed to the lateral force caused by the flow of liquefied soil. For better understanding, a close-up plot of the time histories of the monotonic components of the back-calculated shear forces at the pile heads before the onset of plastic deformation is also depicted in Fig. 35. Then, the profiles of the shear forces at different time steps along each pile were obtained using Eq. (5), and Fig. 36 displays an example for the case of pile B2. As can be seen in Fig. 36, the monotonic component of the shear force attained large values at the pile head and decreased to a negligible value at the bottom. 


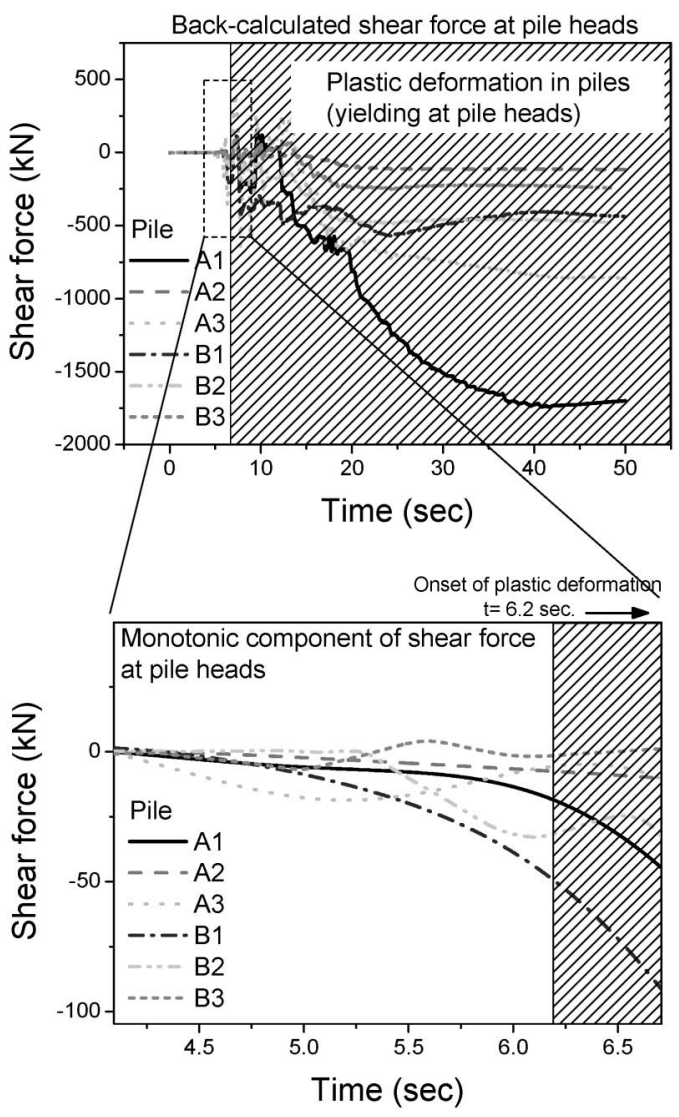

Fig. 35. Time histories of back-calculated shear force at pile heads

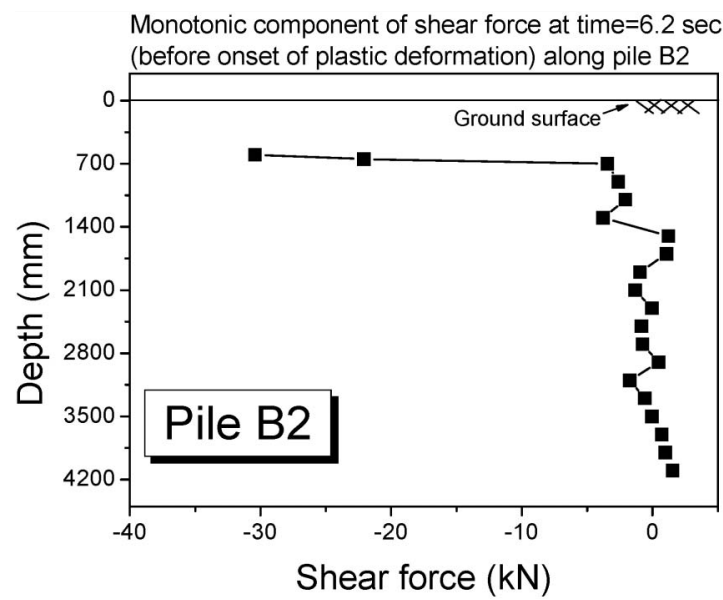

Fig. 36. Profile of monotonic component of shear force along pile B2 at time $=6.2$ seconds (before onset of plastic deformation)

Therefore, it was reasonable to assume that the shear force at the top is equal to the entire lateral force exerted by the liquefied soil on a pile. Next, the shear force at the pile heads at the time of 6.2 seconds was used to plot Fig. 37 which clearly illustrates that the rear row piles (close to the quay wall) received greater shear forces than the front row piles (far from the quay wall). This observation is consistent with the results obtained from EP sensors (Fig. 29).

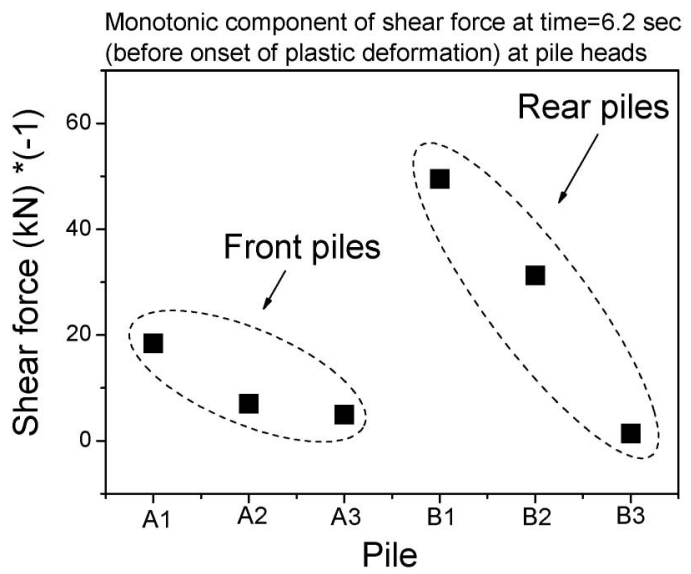

Fig. 37. Comparison between monotonic components of shear force at pile heads at time $=6.2$ seconds (before onset of plastic deformation)

\section{RATE-DEPENDENT BEHAVIOUR OF LIQUEFIED SOIL}

Authors have been studying the rate-dependent nature of liquefied sand and in this paper an attempt was made to confirm it using the results of the large-scale experiment in E-Defense.

Figures 38 and 40 display that both soil and pile lateral displacements increased steadily during the shaking, approaching residual values at the end. However, lateral force recorded by the EP sensors followed a different pattern; a sudden rise in the early stage of shaking, then some fluctuations, and finally displaying a residual value. Since the lateral force showed correlation with neither soil nor pile displacements during the shaking, the relative velocity between soil and pile was calculated, and two examples are depicted in Figs. 39 and 41. As can be seen, the lateral force of the liquefied soil demonstrated a fairly close correlation with the relative velocity at deep depth $(3700 \mathrm{~mm})$ during the shaking until a certain time $(25 \mathrm{sec}-$ onds) considering the limitation of EP sensor records (see Fig. 26), while this correlation was poor at the shallow depth $(900 \mathrm{~mm})$. This discrepancy can be attributed to several factors which affected the recorded lateral force by the EP sensors at shallow depths including: (1) all the piles were yielded at the top and consequently weight of the footing pushed the piles (Fig. 6), (2) considerable tilting of the piles and large settlement of the surface ground produced a geometrical-induced lateral force in the piles which were significant after the lateral spreading stopped (25 seconds). Furthermore, the measurement of the lateral soil displacement inside the pile group at the shallow depth was less reliable, because Inclinometer B was hit by the tilting footing as described in Lateral Soil Displacement. Therefore, the time history of the EP which recorded lateral forces was more reliable at deep depths rather than shallow depths in this experiment.

Hence, the agreement between the lateral force and the relative velocity at deep depth $(3700 \mathrm{~mm})$ seems to confirm the rate-dependent behaviour of the lateral force of 


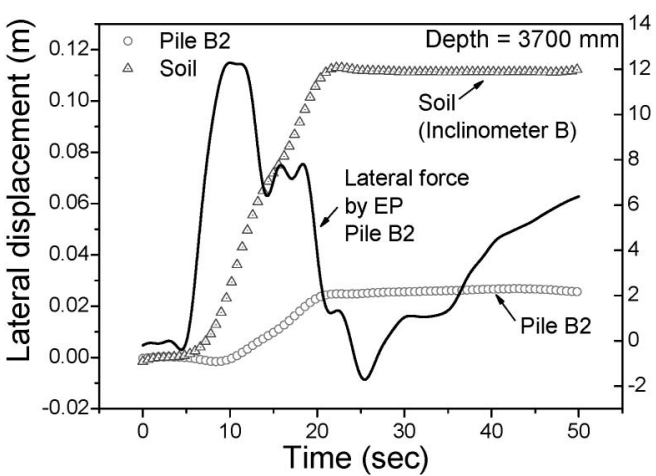

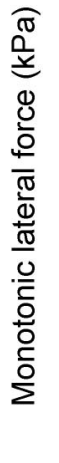

Fig. 38. Time histories of soil and pile displacements, and lateral force of liquefied soil at depth $=3700 \mathrm{~mm}$ in Pile B2

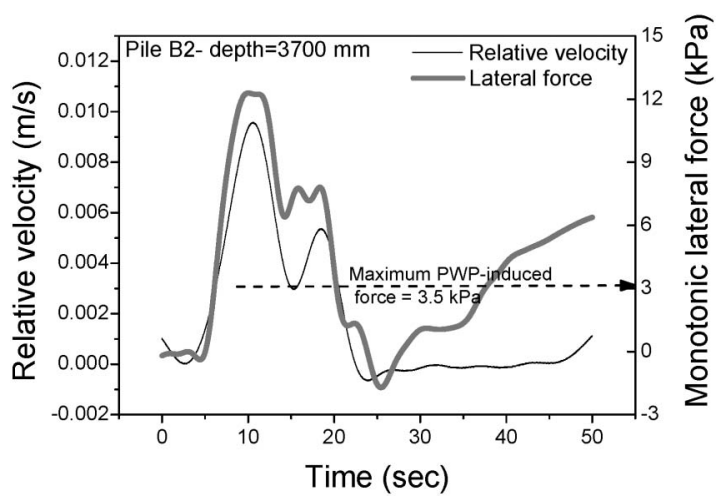

Fig. 39. Time histories of lateral force of liquefied soil, relative velocity, and maximum PWP-induced force at depth $=3700 \mathrm{~mm}$ in Pile B2

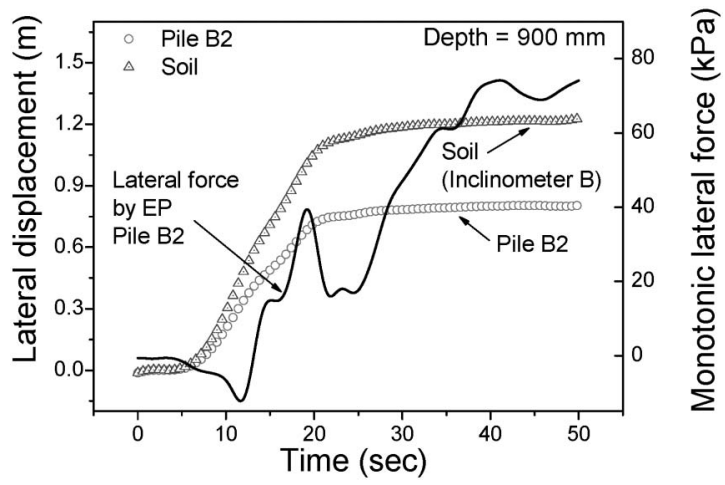

Fig. 40. Time histories of soil and pile displacements, and lateral force of liquefied soil at depth $=900 \mathrm{~mm}$ in Pile B2

liquefied soil during the shaking until the time 25 seconds. In other words, liquefied soil in the lateral flow appears to be similar to a viscous liquid, and this conclusion could be applied to the numerical modelling of lateral spreading. However, it should be noted that more data from full scale experiments, field testing, 1 -g shaking table model tests and centrifuge model tests are needed in this respect.

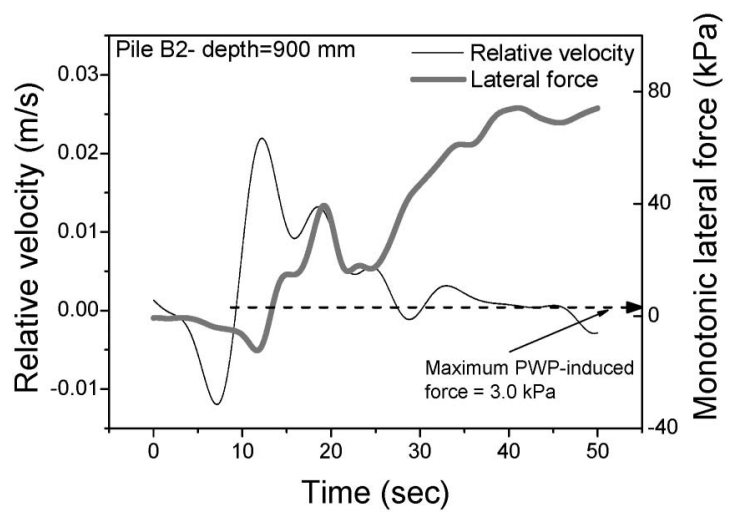

Fig. 41. Time histories of lateral force of liquefied soil, relative velocity, and maximum PWP-induced force at depth $=900 \mathrm{~mm}$ in Pile B2

\section{CONCLUSIONS}

A large-scale test on a pile group behind a sheet pile quay wall was conducted in E-Defense and the following conclusions are drawn:

1. Inclinometers were able to measure the lateral soil displacement fairly well. Maximum lateral displacement and velocity of soil flow were observed at the ground surface, reduced with increasing the depth and decreased as distance from the quay wall increased toward the landside.

2. Recorded bending strain in the piles displayed a strong agreement with the plastic deformation of the piles: negative strain at the pile heads representing yielding and positive values at middle height of the piles indicating buckling.

3. PWP records in front (landward) and back (seaward) sides of the piles were mainly in phase and almost identical particularly during the early stage of high PWP built up. The slight differences at the lateral spreading period were caused by the inclination of the piles. In addition, the PWP-induced lateral force was found to be insignificant compared to the lateral force of the liquefied soil recorded by the EP sensors.

4. The directly measured lateral force of the liquefied soil by the EP sensors showed that the rear row piles (close to the quay wall) received larger lateral forces rather than the front row piles (far from the quay wall) as a result of large displacement and velocity of the soil behind the quay wall. In addition, it was illustrated that the JRA2002 design code underestimated the lateral force of the liquefied soil especially for the rear row piles.

5. Back calculation approach to obtain shear and lateral forces of liquefied soil in piles would be a reliable method as far as the pile response could be assumed to be linearly elastic. Hence, a careful application of the back-calculation approach is highly recommended.

6. A fairly close correlation at deep depth was established between the lateral force of liquefied soil and the relative velocity of soil flow. Since the time history 
of EP sensor records at shallow depths were erroneous because of several problems such as pile inclinations, footing tilting and large ground settlement, this correlation at the shallow depths could not be examined in detail.

\section{ACKNOWLEDGMENTS}

The large-scale experiment described in this paper was a part of "Special Project for Mitigation of Earthquake Disaster in Urban Areas" which was sponsored by the Japan Ministry of Education, Culture, Sports, Science, and Technology (MEXT) and carried out at the National Research Institute for Earth Science and Disaster Prevention (NIED). These supports are highly acknowledged. The authors also appreciate the coordination of Prof. Kohji Tokimatsu from Tokyo Institute of Technology as the research group leader. Information regarding the EP sensors was provided by Dr. Hiroko Suzuki which is greatly acknowledged. Moreover, the first author wishes to express his sincere appreciation to Prof. Junichi Koseki from the University of Tokyo for his invaluable comments and constructive discussions.

\section{REFERENCES}

1) Abdoun, T., Dobry, R., O'Rourke, T. D. and Goh, S. H. (2003): Pile response to lateral spreads: centrifuge modelling, Journal of Geotechnical and Geoenvironmental Engineering, ASCE, 129(10), 869-878.

2) Cubrinovski, M., Kokusho, T. and Ishihara, K. (2006): Interpretation from large-scale shake table tests on piles undergoing lateral spreading in liquefied soils, Soil Dynamics and Earthquake Engineering, 26, 275-286.

3) Fukutake, F. (2006): Personal communication.

4) Gallage, C. P. K., Towhata, I. and Nishimura, S. (2005): Laboratory investigation on rate-dependency properties of sand undergoing low confining effective stress, Soils and Foundations, 45(4), 43-60.

5) Gonzalez, M. (2004): Model tests on group pile foundation undergoing lateral flow of liquefied soil, Master Thesis, Department of Civil Engineering, The University of Tokyo, Tokyo, Japan, September 2004

6) Hamada, H., Yasuda, S., Isoyama, R. and Emoto, K. (1986): Study on liquefaction induced permanent ground displacements, Research Report, Association for the Development of Earthquake Prediction, Japan.

7) Imamura, S., Hagiwara, T., Tsukamoto, Y. and Ishihara, K. (2004): Response of pile groups against seismically induced lateral flow in centrifuge model tests, Soils and Foundations, 44(3), 39-55.

8) Ishihara, K., Yasuda, S. and Nagase, H. (1996): Soil characteristics and ground damage, Soils and Foundations, Special Issue on Geotechnical Aspects of the January 171995 Hyogoken-Nambu Earthquake, 109-118.

9) Japan Road Association (2002): Specifications for Highway Bridges-Part $V$ Seismic Design, Tokyo, Japan.

10) MEXT and NIED (2006): Research Theme No. 2, Annual Report of the Fiscal Year 2005, Special Project for Earthquake Disaster Mitigation in Urban Areas, Ministry of Education Culture Sports Science and Technology and National Research Institute for Earth Science and Disaster Prevention (in Japanese).

11) Motamed, R. (2007): Shaking table tests on pile groups subjected to liquefaction-induced large ground deformation, Ph.D. Dissertation, Department of Civil Engineering, The University of Tokyo, Tokyo, Japan, September 2007.

12) Motamed, R., Towhata, I. and Sesov, V. (2007): Study on $p-y$ curve for piles subjected to lateral flow of liquefied ground, 4th International Conference on Earthquake Geotechnical Engineering, Thessalonica, Greece, June 25-28, paper no. 1212.

13) Nishimura, S., Towhata, I. and Honda, T. (2002): Laboratory shear tests on viscous nature of liquefied sand, Soils and Foundations, 42(4), 89-98.

14) Ogawa, N., Ohtani, K., Katayama, T. and Shibata, H. (1999): World's largest shaking table takes shapes in Japan-A summary of construction plan and technical development, SmiRT.

15) Ohtani, K., Ogawa, N., Katayama, T. and Shibata, H. (2003): Construction of E-Defense (3-D full-scale earthquake testing facility), Proc. 2nd International Symposium on New Technologies for Urban Safety of Mega Cities in Asia, 69-76.

16) Orense, R., Ishihara, K., Yasuda, S., Morimoto, I. and Takagi, M. (2000): Soil spring constants during lateral flow of liquefied ground, 12th World Conference on Earthquake Engineering, New Zealand, paper no. 2099.

17) Rollins, K. M., Lane, J. D. and Gerber, T. M. (2005): Measured and computed lateral response of a pile group in sand, Journal of Geotechnical and Geoenvironmental Engineering, ASCE, 131(1), 103-114.

18) Rollins, K. M., Gerber, T. M., Lane, J. D. and Ashford, S. A. (2005): Lateral resistance of a full-scale pile group in liquefied sand, Journal of Geotechnical and Geoenvironmental Engineering, ASCE, 131(1), 115-125.

19) Sato, M. and Inoue, T. (2003): General framework of research topics utilizing the 3-D full-scale earthquake testing facility, Proc. 2nd International Symposium on New Technologies for Urban Safety of Mega Cities in Asia, 77-86.

20) Suzuki, H., Tokimatsu, K., Sato, M. and Tabata, K. (2007): Soilpile-structure interaction during multi-dimensional shaking through physical model tests using E-Defense facility, 4th International Conference on Urban Earthquake Engineering, March 5-6, Tokyo Institute of Technology, 841-848.

21) Tabata, K., Sato, M., Tokimatsu, K., Suzuki, H. and Tokuyama, H. (2007): E-Defense shaking table test of model ground with a quay wall on liquefaction-induced lateral spreading, 4th International Conference on Urban Earthquake Engineering, March 5-6, Tokyo Institute of Technology, 825-832.

22) Tokimatsu, K. and Asaka, Y. (1998): Effects of liquefaction-induced ground displacements on pile performance in the 1995 Hyogoken-Nambu Earthquake, Special Issue of Soils and Foundations, 163-177.

23) Tokimatsu, K., Suzuki, H. and Suzuki, Y. (2001): Back-calculated $p-y$ relation of liquefied soils from large shaking table tests, Proc. 4th International Conference on Recent Advances in Geotechnical Earthquake Engineering and Soil Dynamics, San Diego, California, paper no. 6.24

24) Tokimatsu, K. and Suzuki, H. (2004): Pore water pressure response around pile and its effects on $p-y$ behavior during soil liquefaction, Soils and Foundations, 44(6), 101-110.

25) Tokimatsu, K., Suzuki, H. and Sato, M. (2005): Effects of inertial and kinematic interaction on seismic behaviour of pile with embedded foundation, Soil Dynamics and Earthquake Engineering, 25, 753-762.

26) Tokimatsu, K., Suzuki, H., Tabata, K. and Sato, M. (2007): Threedimensional shaking table tests on soil-pile-structure models using E-Defense facility, 4th International Conference on Earthquake Geotechnical Engineering, Thessaloniki, Greece, June 25-28, paper no. 1529.

27) Towhata, I., Vargas-Monge, W., Orense, R. P. and Yao, M. (1999): Shaking table tests on subgrade reaction of pipe embedded in sandy liquefied subsoil, Soil Dynamics and Earthquake Engineering, 18, 347-361.

28) Towhata, I., Sesov, V. and Motamed, R. (2006): Model tests on lateral earth pressure on large group pile exerted by horizontal displacement of liquefied sandy ground, 8th U.S. National Conference on Earthquake Engineering and 100th Anniversary Earthquake Conference, San Francisco, California, April 18-22, paper no. 1227. 